\title{
Joining of Half-Heusler and Bismuth Tellurides for Segmented Thermoelectric
} Generators

\author{
Ngan, Pham Hoang; Han, Li; Christensen, Dennis Valbjørn
}

Published in:

Journal of Electronic Materials

Link to article, DOI:

10.1007/s11664-017-5827-8

Publication date:

2018

Document Version

Peer reviewed version

Link back to DTU Orbit

Citation (APA):

Ngan, P. H., Han, L., \& Christensen, D. V. (2018). Joining of Half-Heusler and Bismuth Tellurides for Segmented Thermoelectric Generators. Journal of Electronic Materials, 47(1), 701-710. https://doi.org/10.1007/s11664-017$5827-8$

\section{General rights}

Copyright and moral rights for the publications made accessible in the public portal are retained by the authors and/or other copyright owners and it is a condition of accessing publications that users recognise and abide by the legal requirements associated with these rights.

- Users may download and print one copy of any publication from the public portal for the purpose of private study or research.

- You may not further distribute the material or use it for any profit-making activity or commercial gain

- You may freely distribute the URL identifying the publication in the public portal 


\title{
Joining of half-Heusler and bismuth tellurides for segmented thermoelectric generators
}

\author{
Pham Hoang Ngan*, Li Han and Dennis Valbjørn Christensen \\ Department of Energy Conversion and Storage, Technical University of Denmark, Roskilde, Denmark \\ *Email: ngan.pham@dlr.de
}

\begin{abstract}
Segmented generators where the $p$ - or $n$-type legs are formed by joining materials in series enables each material to operate in their most efficient temperature range. Here, we have fabricated and characterized segmented thermoelectric $p$ - and $n$-type legs based on bismuth tellurides and halfHeusler alloys $p$-type $\mathrm{Hf}_{0.5} \mathrm{Zr}_{0.5} \mathrm{CoSn}_{0.2} \mathrm{Sb}_{0.8}$ and $n$-type $\mathrm{Ti}_{0.6} \mathrm{Hf}_{0.4} \mathrm{NiSn}$. A two-step process was introduced to join the half-Heusler to the bismuth tellurides to form a segmented structure which was then characterized for its thermoelectric and structural properties. The output power generation was characterized under various hot side temperatures up to $873 \mathrm{~K}$ with the cold side fixed at 323 $\mathrm{K}$. The stability of the joints was also investigated under heat treatment and thermal cycling. Under working temperatures from 323 to $873 \mathrm{~K}$, the obtained $p$-type segmented legs could deliver a power density of $0.3 \mathrm{~W} \cdot \mathrm{cm}^{-2}$ and maximum voltage of $115 \mathrm{mV}$. With the same condition, the power density and the maximum voltage generated by $n$ - type segmented leg were $0.25 \mathrm{~W} \cdot \mathrm{cm}^{-2}$ and 102 $\mathrm{mV}$. The area-specific contact resistance of the $p$ - and $n$ - type legs were $50 \mu \Omega \cdot \mathrm{cm}^{2}$ and $35 \mu \Omega \cdot \mathrm{cm}^{2}$, respectively. The output performance of each leg was $\sim 95 \%$ after 6 cycles from $323 \mathrm{~K}$ to $873 \mathrm{~K}$.
\end{abstract}

Key words: Segmented thermoelectric generator, thermoelectric joining, bismuth telluride, halfHeusler

\section{Introduction}

Although thermoelectric (TE) power generation has many advantages, its conversion efficiency so far is still rather low: less than $10 \%$. One example is thermoelectric generators (TEG) composed of half-Heusler (HH) alloys that are very competitive materials suitable for medium-high temperature range up to about $873 \mathrm{~K}[1,2]$. A unicouple composed of the $p$-type $\mathrm{Fe}_{2} \mathrm{VAl}_{0.9} \mathrm{Si}_{0.1}$ and n-type $\mathrm{Fe}_{2} \mathrm{~V}_{0.9} \mathrm{Ti}_{0.1} \mathrm{Al}$ Heusler alloys has an efficiency of $1.4 \%$ with hot side temperature of $573 \mathrm{~K}$ and cold side temperature of $293 \mathrm{~K}$ [3]. Recently, unicouple of $\mathrm{Hf}_{0.3} \mathrm{Zr}_{0.7} \mathrm{CoSn}_{0.3} \mathrm{Sb}_{0.7}$ and $\mathrm{Hf}_{0.6} \mathrm{Zr}_{0.4} \mathrm{NiSn}_{0.995} \mathrm{Sb}_{0.005}$ have been found to possesses the conversion efficiency of $8.7 \%$ with $T_{h}=$ $970 \mathrm{~K}$ and temperature gradient of $948 \mathrm{~K}$ [4]. Segmentation of HH with bismuth telluride (BiTe), the dominant material at the low temperature range up to $473 \mathrm{~K}$ [5-7] is predicted from numerical modeling to improve the thermal conversion efficiency of TEG [5,8-10]. In particular, calculations predicted [6] that a segmented leg of BiTe with $\mathrm{HH}$ could reach a maximum efficiency of more than 
$10 \%$ at hot side and cold side temperatures of $900 \mathrm{~K}$ and $300 \mathrm{~K}$, respectively. Therefore, this work is aimed at segmenting these two materials and pave the way to develop high efficiency segmented TEG.

Since different TE materials often have different physical and chemical characteristics, joining these materials is considered to be the most challenging part in fabricating segmented TEGs $[5,10,11]$. The joining process requires strong adhesion, good chemical stability, and low contact resistance between the materials [10-13]. Joining $\mathrm{HH}$ and BiTe is no exception and poses major challenges. BiTe is suitable at temperatures below $523 \mathrm{~K}$ and deteriorates above $773 \mathrm{~K}$ due to the degradation of the material [7,14-18]. HH, however, is composed of thermally stable materials with melting points exceeding $1773 \mathrm{~K}$, depending on composition. The low wettability, however, results in a low capability to form bonds with other materials [19,20]. According to D'Angelo and Börner et al. [21,22], in order to directly join two different materials, the temperature at their interface should be elevated to the range from 50 to $80 \%$ of the lowest melting point. Thus, $\mathrm{HH}$ and BiTe cannot be joined directly together due to their large difference in melting temperature. In this work, segmentations of $\mathrm{BiTe}$ (n-type $\mathrm{Bi}_{2} \mathrm{Te}_{3}$ and $p$-type $\mathrm{Bi}_{0.6} \mathrm{Sb}_{1.4} \mathrm{Te}_{3}$ ) with $\mathrm{HH}$ materials (n-type $\mathrm{Ti}_{0.6} \mathrm{Hf}_{0.4} \mathrm{NiSn}$ and $p$-type $\mathrm{Hf}_{0.5} \mathrm{Zr}_{0.5} \mathrm{CoSn}_{0.2} \mathrm{Sb}_{0.8}$ ) were made using a two-step process. The obtained segmented legs were then investigated in detail.

\section{Experimental}

\subsection{Material preparation}

$p$ - and $n$-type $\mathrm{HH}$ thermoelectric alloys with nominal compositions $\mathrm{Hf}_{0.5} \mathrm{Zr}_{0.5} \mathrm{CoSn}_{0.2} \mathrm{Sb}_{0.8}$ and $\mathrm{Ti}_{0.6} \mathrm{Hf}_{0.4} \mathrm{NiSn}$, respectively, were prepared by arc melting the stoichiometric mixture of the pure elements. The arc-melted ingots were then ball milled (Planetary ball mill PM 100) into fine powder with particle size distribution ranging from 1 to $10 \mu \mathrm{m}$. The powders were then consolidated into bulk samples by spark plasma sintering (SPS 515S). The sintering was done at a pressure of 50 $\mathrm{MPa}$ and a temperature of $1200{ }^{\circ} \mathrm{C}$ for $p$-type and at $1050{ }^{\circ} \mathrm{C}$ for $n$-type with the ramping rate of 50 ${ }^{\circ} \mathrm{C}$ per min for both types. The sintering processes took $30 \mathrm{~min}$ for each sample. BiTe ingots of $p$ type $\mathrm{Bi}_{0.6} \mathrm{Sb}_{1.4} \mathrm{Te}_{3}$ and $n$-type $\mathrm{Bi}_{2} \mathrm{Te}_{3}$ were purchased commercially and their TE properties were measured.

The electrical resistivity and Seebeck coefficient of the materials were measured using ZEM 3 (ULVAC) with measurement uncertainties of 3-5\% for the electrical resistivity and 5-7\% for the Seebeck coefficient. The thermal conductivity $(\kappa)$ was calculated from the thermal diffusivity $(\alpha)$, the mass density $(D)$ and the specific heat capacity $\left(C_{p}\right)$ according to the equation $\kappa=\alpha D C_{p}[1]$ The thermal diffusivity was obtained by the laser flash method (Netzsch LFA-457), the mass densities of the samples were measured by Archimedes' method using water with surfactant, and the 
specific heat capacity was measured using a differential scanning calorimeter (Netzsch DSC 404C). The uncertainty of the thermal conductivity is $7-10 \%$.

\subsection{Segmentation of BiTe and HH}

From the obtained ingots, BiTe and $\mathrm{HH}$ were cut into rectangular pieces and assembled into segmented TE leg with a cross sectional area of $4 \times 4 \mathrm{~mm}^{2}$ and a total length of $8 \mathrm{~mm}$. The length of $8 \mathrm{~mm}$ was chosen to be suitable for further characterization steps and to maintain the temperature gradient of $843 \mathrm{~K}$. The surfaces of the samples were polished with sandpaper and then cleaned before the joining process. Polished samples of $p$ - and $n$-type $\mathrm{HH}$ were ultrasonically treated in acetone, isopropanol and de-ionized water, followed by carbon dioxide cleaning.

$\mathrm{HH}$ alloys and BiTe were joined using a fast hot pressing technique with details described in reference [9]. Much effort has been made to join $\mathrm{HH}$ with the BiTe in a single-step process [־remove second hyphen] by various joining materials chosen to minimize mismatch of thermal expansion coefficients which is a well-known source of delamination and cracking at high temperature [23]. The thermal expansion coefficient (CTE) of BiTe is $\sim 16.4 \mu \mathrm{K}^{-1}[24,25]$ and that of $\mathrm{HH}$ is $\sim 13 \mu \mathrm{K}^{-1}$ [9]. Thus, different solder alloys were used such as, $\mathrm{Ag}_{10} \mathrm{Sn}$ ( $\mathrm{Ag} 10 \%$ wt and $\mathrm{Sn}$ $90 \% \mathrm{wt})\left(\mathrm{CTE}=22 \mu \mathrm{K}^{-1}\right)$ or $\mathrm{Cu}\left(\mathrm{CTE}=16.5 \mu \mathrm{K}^{-1}\right)$, Ni $\left(\mathrm{CTE}=13 \mu \mathrm{K}^{-1}\right)$, and $\mathrm{Al}\left(\mathrm{CTE}=22 \mu \mathrm{K}^{-1}\right)$. However, the joining was not successful mainly due to the poor wettability of half-Heusler with the molten solders. The problem was also encountered in Ref. [20,26]. We therefore developed a twostep procedure to join $\mathrm{HH}$ and BiTe. First, $\mathrm{HH}$ was joined with Ag by hot pressing at $1053 \mathrm{~K}$ under a pressure of $40 \mathrm{MPa}$ in vacuum following the joining process described in [9]. Following the coating of $\mathrm{Ag}$, the $\mathrm{Ag}$ surface of the joined $\mathrm{HH} / \mathrm{Ag}$ was cleaned with acetone and ethanol. A $0.3 \mu \mathrm{m}$ thick foil of $\mathrm{Ag}_{10} \mathrm{Sn}$ solder alloy was placed on top of the cleaned $\mathrm{Ag}$ surface and joined with the BiTe segment. The TE leg was placed into a spark plasma sintering (SPS) chamber and processed at $493 \mathrm{~K}$, under a pressure of $30 \mathrm{MPa}$ in vacuum. These joining conditions were optimized based on the melting temperature of the solder alloy and the maximum load that BiTe can maintain without cracking. A custom-made alumina structure was used to prevent the current in the SPS from flowing through the TE materials since the high current density would cause local superheating and current effects at interfaces, thus affect the TE properties of the materials [2].

\subsection{Characterization of the as-joined interface.}

The obtained segmented sample was cut into different pieces perpendicular to the direction of the joining interface to analyze the microstructural and electrical properties across the interface. The microstructures and chemical distributions of elements at the joint were analyzed by scanning electron microscopy (SEM) and energy dispersive X-ray spectroscopy (EDS) (Zeiss Supra-35). The thermopower of adjacent materials at the joined interfaces were scanned by a Seebeck scanning microprobe (Panco) with scanning probe resolution of $50 \mu \mathrm{m}$ as described elsewhere [9]. The 
contact resistances of the joined samples were measured (Fig. 1b) using a 4-probe scanning method described also in [9] with measurement uncertainty of 1-3\%, excluding geometric uncertainty. Characterizations of the obtained $\mathrm{BiTe} / \mathrm{HH}$ were carried out with increasing temperature from $50 \mathrm{~K}$ to $473 \mathrm{~K}$ due to the melting limitation of solder $\mathrm{Ag}_{10} \mathrm{Sn}$. The stability of the joint materials was studied at $473 \mathrm{~K}$ for $48 \mathrm{~h}$ in a flowing nitrogen environment to minimize a possible oxidation of BiTe and sublimation of tellurium and antimony (in p-type BiTe) [2,27]. Characterization of the materials was done before and after the heat treatment.

\subsection{Characterization of $p$ - and $n$ - BiTe/HH segmented legs}

The electrical resistivity and Seebeck coefficient of the segmented leg, including the interface layer have been measured by using ZEM 3 (ULVAC). Finally, the voltage-current characteristics of the legs were measured at a constant temperature span with a measurement uncertainty of $1.2 \%$. Details of the test system is described in [8].

\section{Results and discussion}

\subsection{Thermoelectric properties of bismuth tellurides and half-Heusler materials}

The electrical resistivity $(\rho)$, Seebeck coefficient $(S)$ and thermal conductivity $(\kappa)$ as a function of temperature for BiTe and $\mathrm{HH} p$ - and $n$-type materials are shown in Fig. 1 . Both $p$ - and $n$-type BiTe show a metallic-like behavior of the electrical resistivity, similar to that of $p$-type $\mathrm{HH}$. As for $n$-type $\mathrm{HH}$, the electrical resistivity exhibits a semiconductor-like behavior. The absolute values of the Seebeck coefficient of both types of BiTe peaked at $\sim 220 \mu \mathrm{V} \cdot \mathrm{K}^{-1}$ at $373 \mathrm{~K}$ and $423 \mathrm{~K}$ for $n$ - and $p$-type, respectively. The Seebeck coefficient of $p$-type $\mathrm{HH}$ increased over the whole measured temperature range to a maximum value of $220 \mu \mathrm{V} \cdot \mathrm{K}^{-1}$ at $873 \mathrm{~K}$. Meanwhile, the Seebeck coefficient of $n$-type $\mathrm{HH}$ increased to a value of $260 \mu \mathrm{V} \cdot \mathrm{K}^{-1}$ at $623 \mathrm{~K}$ and then decreased upon raising the temperature, reaching a value of $190 \mu \mathrm{V} \cdot \mathrm{K}^{-1}$ at $873 \mathrm{~K}$ due to bi-polar conduction effect. By segmenting BiTe and $\mathrm{HH}$, the average $Z T$ of $p$ - and $n$-type segmented legs, calculated by averaging $z T$ across the temperature range $(300-873 \mathrm{~K})$, with $z T=S^{2} T / \rho \kappa[5]$ were 0.4 and 0.5 , respectively. 

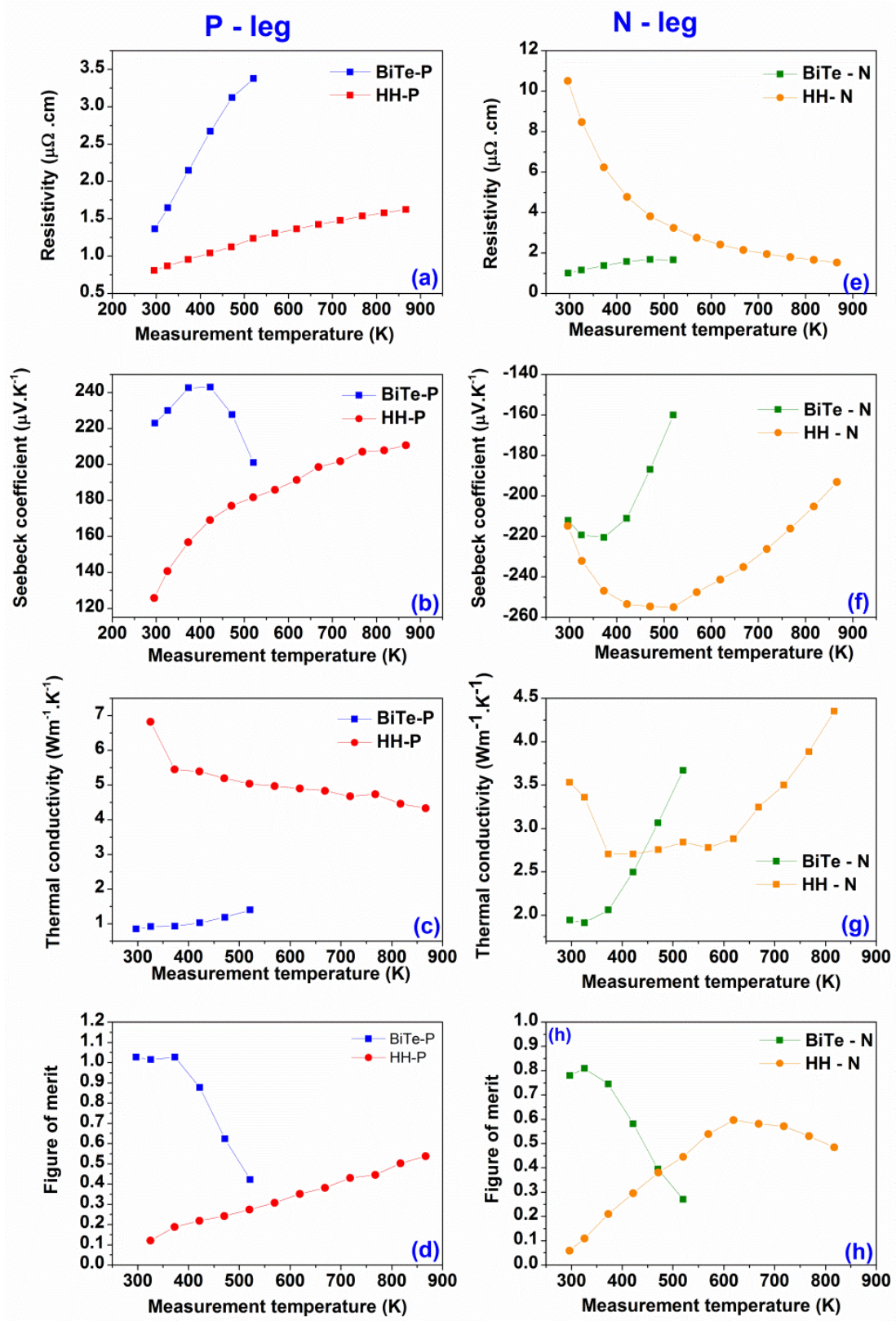

Fig.1. Thermoelectric properties of BiTe and HH in $p$-type (a-d) and $n$-type segmented leg (e-h).

\subsection{Interfacial microstructural and thermoelectric analyses}

Microstructure and chemical analysis at the interface of the $p$ - and the $n$-type segmented TE elements are shown in Fig. 2. For both the $p$ - and the $n$-type no sign of delamination and cracks between joining layers were observed. In both $p$ - and $n$-type cases, EDS analyses show that in the solder layer, there are regions of Sn- and Ag-rich phases: points (3) and (4) in Fig. 2(b) and 2(f). A small amount of $\mathrm{Sb}$ was also detected in the solder layer, which might be the consequence of diffusion from BiTe to form an interphase with $\mathrm{Sn}$ in the solder [28]. An intermediate region rich in Sn with thickness of $\sim 10 \mu \mathrm{m}$ formed towards the BiTe side, indicating the diffusion of Sn into BiTe, 
which was also observed in several other works [29-31]. The compositions of these interface regions were quantified in Table II (see Appendix).

After heat treatment, the development of the interdiffusion layer between BiTe and solder alloy $\mathrm{Ag}_{10} \mathrm{Sn}$ is observed in the $n$-type leg. The total thickness of the $\mathrm{Ag}_{10} \mathrm{Sn} /$ interdiffusion layers increased from $40 \mu \mathrm{m}$ to $60 \mu \mathrm{m}$ after heat treatment. EDS analysis of the interdiffusion layer showed that there is a tendency of Sn to diffuse into BiTe to form SnTe-rich phases [29]. After $48 \mathrm{~h}$ of heat treatment, the diffusion layer between BiTe and solder alloy expanded by $30 \mu \mathrm{m}$ (from 10 to $40 \mu \mathrm{m})$. The $p$-type segmented leg however, delaminated after the heat treatment. The delamination could be due to the fast diffusion of Sn into $p$-type BiTe that degraded the solder layer [33-35]. The interdiffusion layer between BiTe and HH became more visible after heat treatment (Fig. $2 \mathrm{f}$ and $2 \mathrm{k})$.

The Seebeck coefficient profiles of the joined interfaces for $p$ - and $n$-type segmented leg are shown in Fig. 3. The $\sim 200 \mu \mathrm{m}$ thickness of Ag filler corresponds well with the region with low Seebeck coefficients in the range of $0-10 \mu \mathrm{V} \cdot \mathrm{K}^{-1}$ on the scanned area. The intermediate region between BiTe and $\mathrm{Ag}_{10} \mathrm{Sn}$ solder was observed in the $p$-segmented leg. As reflected from the SEM and EDS analysis, this intermediate region is likely due to the newly formed diffusion layer composed of ( $\mathrm{Sn}, \mathrm{Sb})$ and $(\mathrm{Sn}, \mathrm{Te})$-rich phases between BiTe and the solder. It can be interpreted from the Seebeck coefficient mapping results that this intermetallic layer has a thermopower of $\sim 110 \mu \mathrm{V} \cdot \mathrm{K}^{-1}$, which is lower than the $\sim 180 \mu \mathrm{V} \cdot \mathrm{K}^{-1}$ in BiTe. Towards the $\mathrm{HH}$ region, changes in thermopower of the TE material after joining were not observed. In the case of the $n$-type segmented leg, the $\mathrm{Ag}$ and solder layer between BiTe and $\mathrm{HH}$ after joining was measured to be $<20$ $\mu \mathrm{V} \cdot \mathrm{K}^{-1}$. This value corresponds well with the Seebeck coefficients of $\mathrm{Ag}\left(\sim 1.5 \mu \mathrm{V} \cdot \mathrm{K}^{-1}[36]\right), \operatorname{Sn}(-$ $\left.1.5 \mu \mathrm{V} \cdot \mathrm{K}^{-1}[37]\right)$ and $\operatorname{SnTe}\left(\sim 25 \mu \mathrm{V} \cdot \mathrm{K}^{-1}[38]\right)$, which were the main components observed from the EDS analysis. 

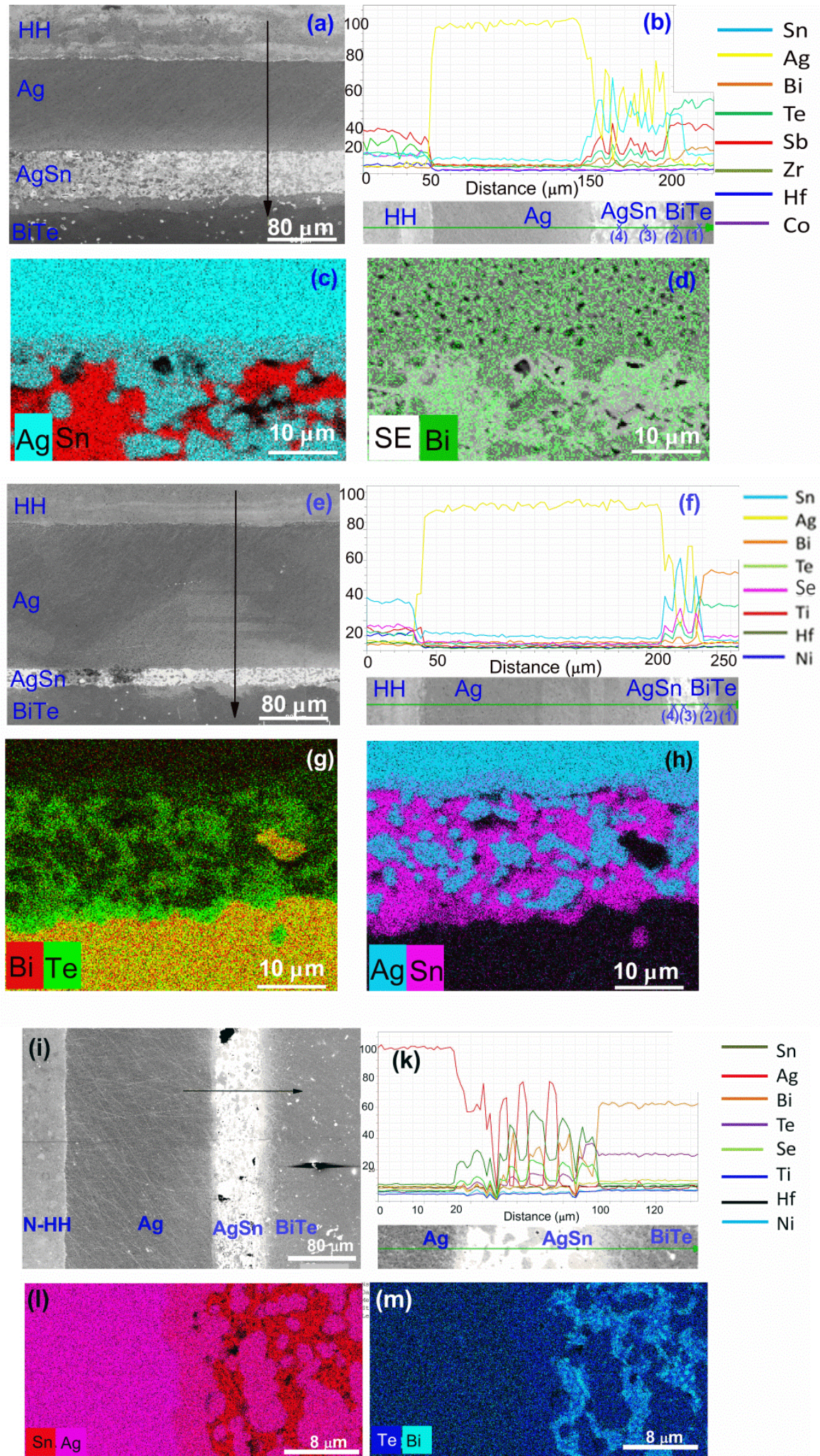

Fig. 2. SEM images and EDS chemical analysis at the joint interface of $p$-type (a-d), $n$-type (e-h) segmented leg before heat treatment and (i-m) $n$-type segmented leg after heat treatment. After heat treatment, the $p$-type segmented leg delaminated, so no further microstructural analysis was conducted. 

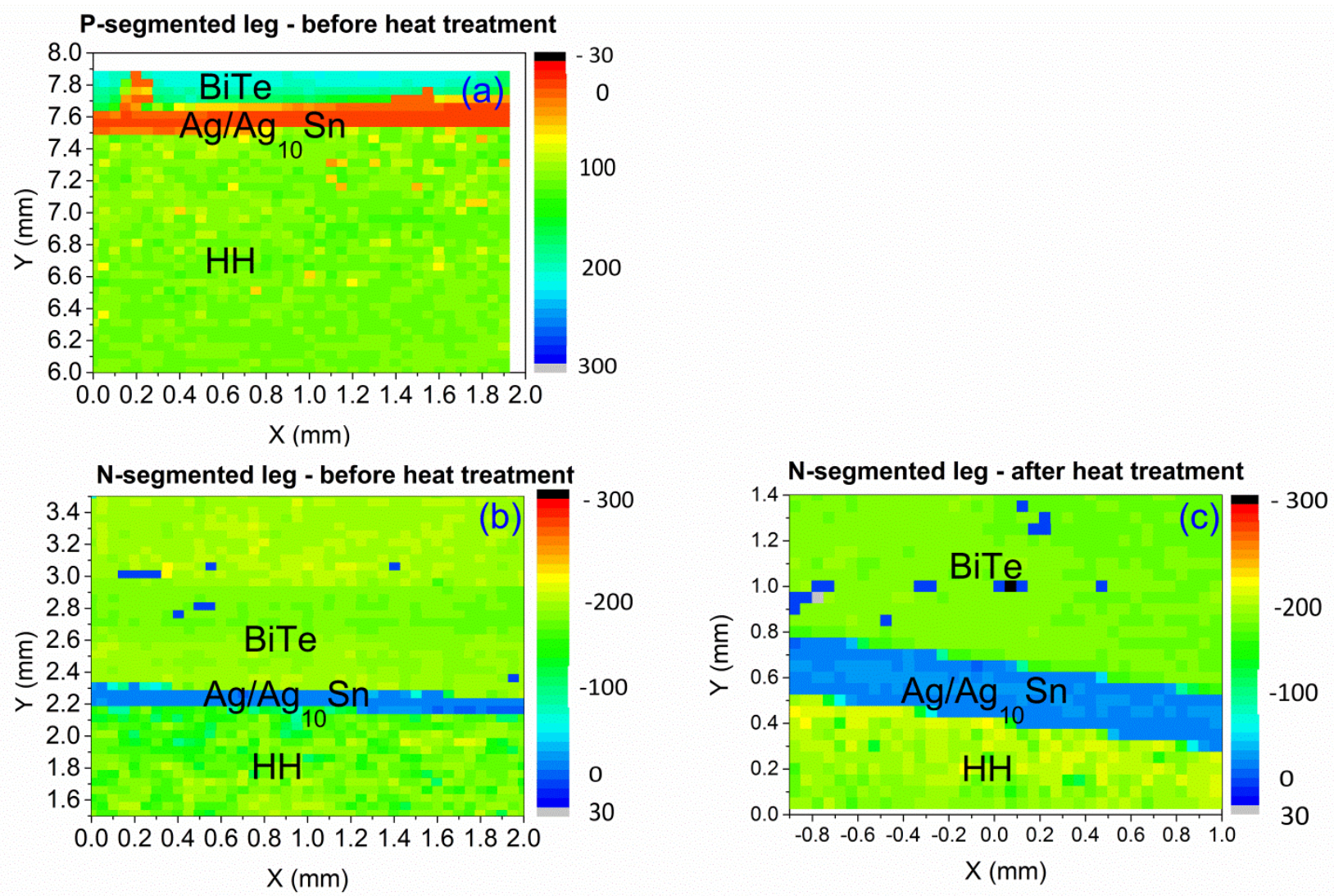

Fig. 3. Scanning Seebeck analysis at the joint interface of $p$-type (a) and $n$-type (b, c) segmented leg

\subsection{Electrical contact resistances}

One of the most critical features of a joined TE element is its area-specific contact resistance. At room temperature, the area-specific contact resistances of the obtained $p$ - and $n$ - type segmented elements are 50 and $40 \mu \Omega \cdot \mathrm{cm}^{2}$, respectively (Fig. 4). These values are competitive compared with other studies where contact resistances were below $100 \mu \Omega \cdot \mathrm{cm}^{2}[8,9,12,39-41]$. This overall specific contact resistance (denoted as $R_{c i}$ ) contains resistances of three interfaces: $\mathrm{HH} / \mathrm{Ag}$, $\mathrm{Ag} / \mathrm{Ag}_{10} \mathrm{Sn}$ and $\mathrm{Ag}_{10} \mathrm{Sn} / \mathrm{Bi}_{2} \mathrm{Te}_{3}$. Over the whole temperature range, the contact resistance of the $p$ type segmented leg was found to be higher than that of the $n$-type segmented leg, presumably due to the presence of SnTe in the interfacial layer between BiTe and $\mathrm{Ag}_{10} \mathrm{Sn}$ solder. SnTe is commonly used as $p$-type semiconductor because of its high $\mathrm{Sn}$ - vacancies characteristic, resulting in high concentrations of holes $[13,38]$. Thus, the $p$-type BiTe/SnTe contact is more likely to have higher contact resistance compared to the $n$-type BiTe/SnTe interface. Observation of high contact resistance for $p$-type TE material and metal interface have been studied and reported by Yamashita [42]. 


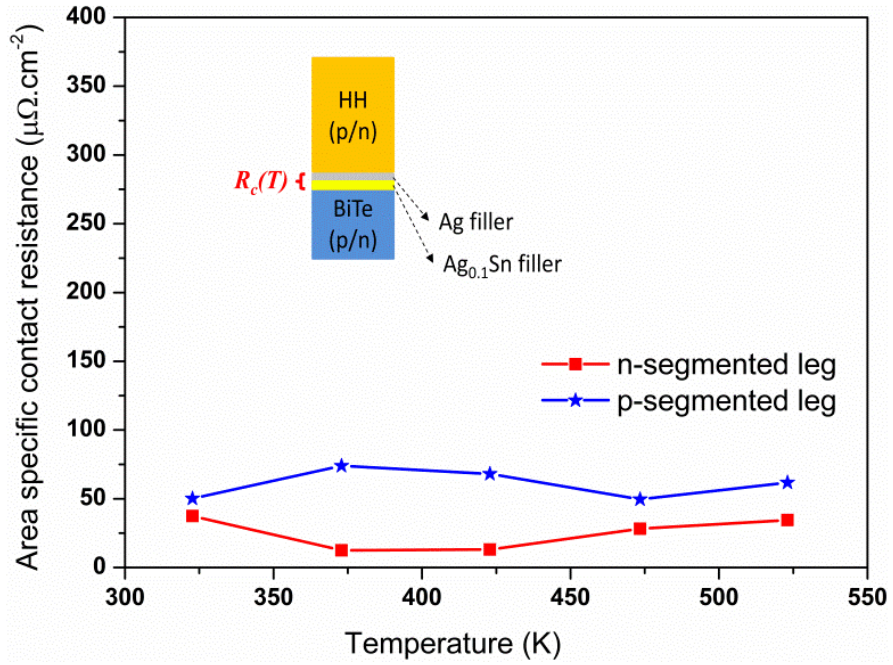

Fig. 4. Temperature-dependence of area specific contact resistance of the $p$ - and $n$-type segmented legs

\subsection{Thermoelectric characteristics of segmented legs}

Thermoelectric properties of the as-prepared segmented legs are shown in Fig. 5. The measured values were also compared with the results from calculation based on reference [44]. Details of the calculation are provided below. The calculation does not take into account any interfacial effects except for the electrical resistances. The electrical conductivity of the segmented legs can be calculated by Eq. 1 below:

$$
\frac{\rho_{\text {seg }} l_{\text {total }}}{A}=\frac{\rho_{\text {BiTe }} l_{\text {BiTe }}+\rho_{H H} l_{H H}+A S R C}{A}
$$

where $A$ is the cross sectional area of the segmented legs which is in this case similar both to $n$ - and $p$-type legs, $A S R c$ is the measured area specific contact resistance, $l_{B i T e}, l_{\text {interlayer }}$, and $l_{H H}$ are the lengths of the BiTe material, interlayer and $\mathrm{HH}$ material, respectively, giving a total length of $l_{\text {total }}=$ $l_{B i T e}+l_{\text {interlayer }}+l_{H H}$. The factors $\rho_{B i T e}, \rho_{H H}$ are the resistivities of the $p / n$-type BiTe and the $p / n$-type HH from (Fig. 1a, 1e), allowing $\rho_{\text {seg }}$ of both $p$ - and $n$-type materials to be calculated.

The measured and the calculated $\rho_{\text {seg }}$ of both $p$ - and $n$ - segmented legs (denoted as $\rho_{p \text {-seg }}$ and $\rho_{n \text { - }}$ seg, respectively) are in good agreement with each other (Fig. 5a and 5c). As it can be seen from Fig. $5 \mathrm{c}$, for the $n$-type segmented leg, the $\rho_{n \text {-seg }}$ shows a semiconductor behavior with the value of $4 \mathrm{~m} \Omega \cdot \mathrm{cm}$ at $323 \mathrm{~K}$ and decreased to $0.2 \mathrm{~m} \Omega \cdot \mathrm{cm}$ at $473 \mathrm{~K}$. The $n$-type segmented leg, on the other hand, shows a metallic behavior: $\rho_{p \text {-seg }}$ increased from 0.8 to $1.4 \mathrm{~m} \Omega \cdot \mathrm{cm}$ as temperature increased from 323 to $473 \mathrm{~K}$ (see Fig. 5a). The measured values were slightly smaller than the calculated ones. It is possible that there is difference in the contact resistance measured by the different equipment. The source of variance is also due to the accurate thickness determination of the intermediate layer using SEM image [45]. All these factors could add up to the discrepancy between measurement and calculation. 
The thermopower of the segmented leg $\alpha_{\text {seg }}$ can be calculated from the intrinsic thermopower of the component materials using the following equation [44]:

$$
\alpha_{\text {seg }}=\frac{\Delta V}{\Delta T}=\frac{\kappa_{H H} \alpha_{B i T e}+\kappa_{B i T e} \alpha_{H H}}{\kappa_{H H}+\kappa_{B i T e}}
$$

where $\kappa_{B i T e}, \kappa_{H H}$ are the thermal conductivities of the BiTe and the HH (Fig. 1c, 1g) and $\alpha_{B i T e}, \alpha_{H H}$ are the Seebeck coefficients of the segmented materials (Fig. 1b, 1f).

The thermopower of $n$-type segmented leg obtained from the measurements are in good agreement with calculations as seen in Fig. 5c. Below $373 \mathrm{~K}, \alpha_{n \text {-seg }}=220 \mu \mathrm{V} \cdot \mathrm{K}^{-1}$, which is slightly smaller than the calculated value of $240 \mu \mathrm{V} \cdot \mathrm{K}^{-1}$. The difference might originate from the uncertainty of the temperature measurement of the thermocouple probe. Another reason is the contribution of thermal contact resistances that needs further thermal contact resistance measurements to determine. The $p$-type segmented leg, however, had measured $\alpha_{p \text {-seg }}$ significantly higher than computed. Calculated $\alpha_{p \text {-seg }}$ was estimated to be from 150 to $180 \mu \mathrm{V} \cdot \mathrm{K}^{-1}$, while measurement showed values from 320 to $230 \mu \mathrm{V} \cdot \mathrm{K}^{-1}$ from 323 to $473 \mathrm{~K}$. This might be due to the geometry of the segmented leg determined to optimize thermoelectric output. For the $p$-type sample, the optimal performance was obtained when the BiTe-part should be only $0.6 \mathrm{~mm}$ thick (details of the calculation are not shown here), while the size of the ZEM3 probe is $0.5 \mathrm{~mm}$. As a consequence, the position of the probe in the measurement was too close to the joining interface and therefore strongly influenced the measured data. 

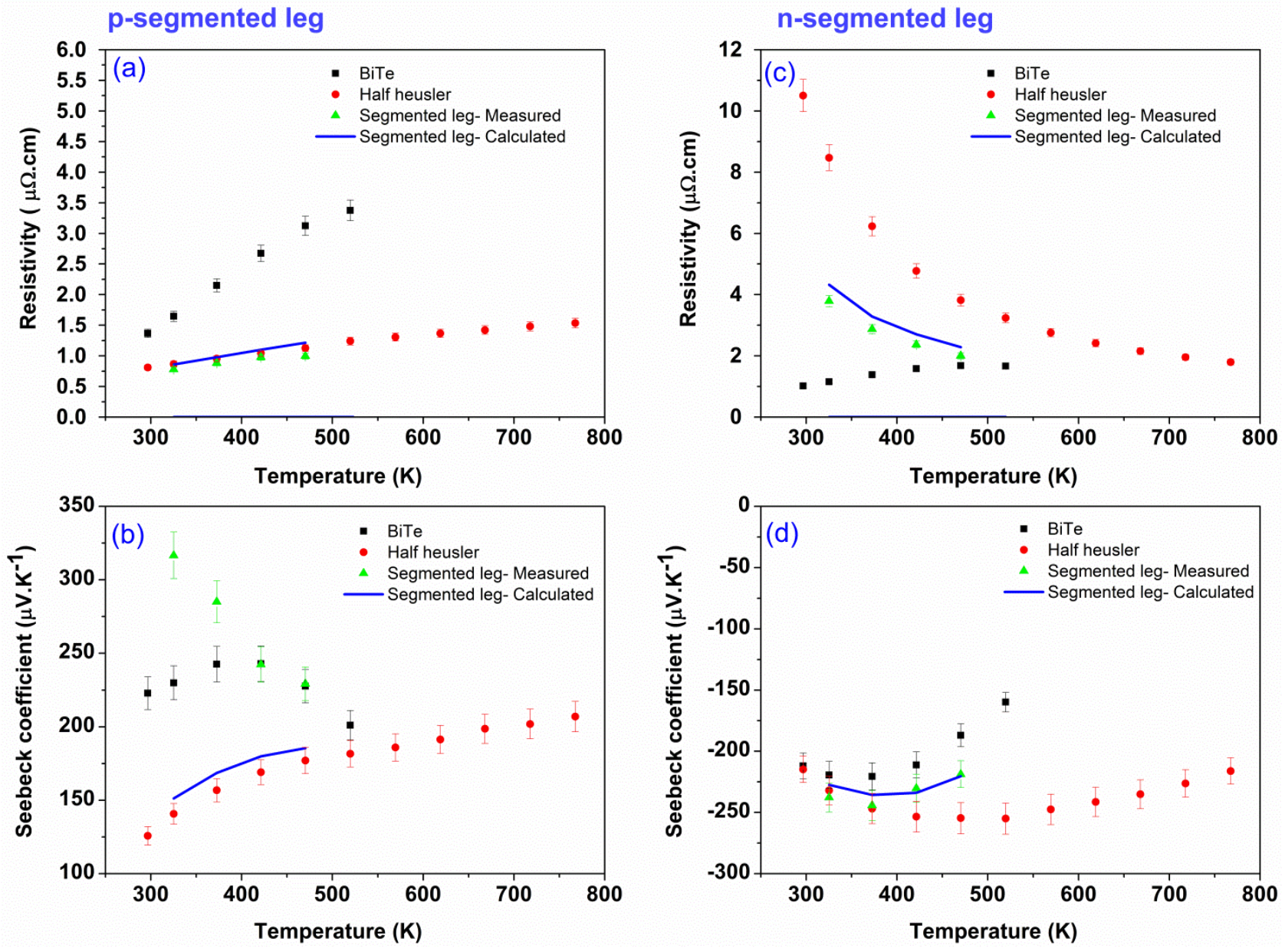

Fig. 5. Resistivity and Seebeck coefficient of $p$-type (a, b) and $n$-type segmented leg (c, d) measured by ZEM3.

\subsection{Output power generating characteristics of segmented legs}

The output power characteristics of the obtained segmented legs at different hot side and cold side temperatures are shown in Fig. $6 \mathrm{a}$ and $6 \mathrm{~b}$. At $\Delta T=550 \mathrm{~K}$, the $p$-type segmented leg generated a maximum open circuit voltage of $115 \mathrm{mV}$ and maximum current of $1.8 \mathrm{~A}$, giving a power output of $49.2 \mathrm{~mW}$ and a power density of $0.3 \mathrm{~W} \cdot \mathrm{cm}^{-2}$. The open voltage and maximum current of the $n$ segmented leg were $102 \mathrm{mV}$ and $1.6 \mathrm{~A}$, respectively under hot side/cold side temperatures of 873 and $323 \mathrm{~K}$, corresponding to a maximum power output of $40.6 \mathrm{~mW}$ and a power density of 0.25 $\mathrm{W} \cdot \mathrm{cm}^{-2}$. It is worth noticing that in this test setup, the electrode at the cold side of the legs is made merely by Ag paste and has not been optimized yet. The Ag paste after drying can introduce a porous layer that results in a large contact resistance observed in Ref $[2,46]$ and therefore negatively influences the overall thermoelectric outputs. 

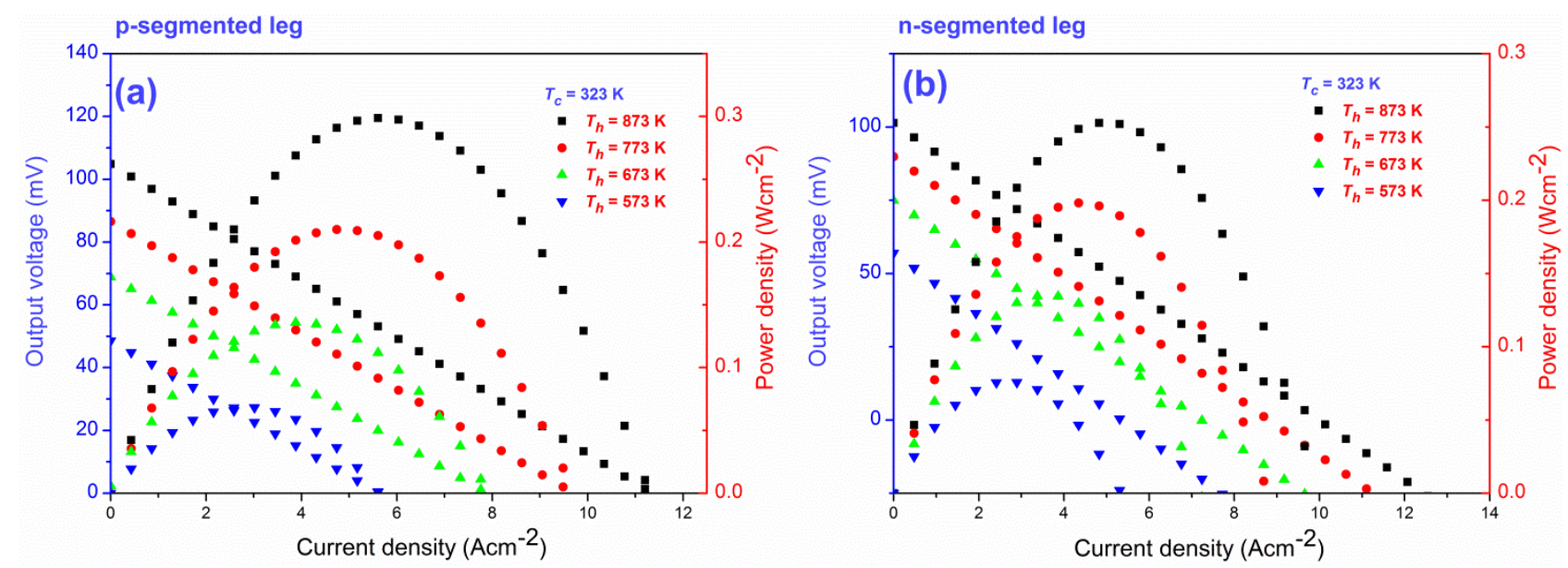

Fig. 6. Output voltage vs. current density characteristics of obtained $p$-type (a) and $n$-type segmented legs (b).

Table I. Comparision of Heusler and half-Heusler-based modules

\begin{tabular}{|c|c|c|c|c|c|}
\hline Module & Material & $\begin{array}{c}\text { Temperature } \\
\text { gradient } \\
\Delta T(\mathrm{~K})\end{array}$ & $\begin{array}{c}\text { Legs } \\
\text { dimensions } \\
(\mathrm{mm})\end{array}$ & $\begin{array}{c}\boldsymbol{P}_{\max } \\
(\mathrm{mW})\end{array}$ & $\begin{array}{c}\text { Power } \\
\text { density } \\
\left(\mathrm{W} \cdot \mathrm{cm}^{-2}\right)\end{array}$ \\
\hline $\begin{array}{c}\text { Heusler } 1 \\
\text { Mikami } \\
\text { [47] }\end{array}$ & $\begin{array}{l}p-\mathrm{Fe}_{2} \mathrm{VAl}_{0.9} \mathrm{Si}_{0.1} \\
n-\mathrm{Fe}_{2} \mathrm{~V}_{0.9} \mathrm{Ti}_{0.1} \mathrm{Al}\end{array}$ & 280 & $\begin{array}{l}\text { 36-times } \\
\text { diameter } \\
5 \times 5\end{array}$ & 940 & 0.133 \\
\hline $\begin{array}{c}\text { Heusler } 2 \\
\text { Mikami } \\
\text { [3] }\end{array}$ & $\begin{array}{c}p-\mathrm{Fe}_{2} \mathrm{~V}_{0.84} \mathrm{Ti}_{0.16} \mathrm{Al}_{0.97} \mathrm{Sb}_{0.03} \\
n-\mathrm{Fe}_{3} \mathrm{VAl}_{0.9} \mathrm{Si}_{0.07} \mathrm{Sb}_{0.03}\end{array}$ & 280 & $\begin{array}{c}36 \text {-times } \\
4.5 \times 4.5 \times \\
4.2\end{array}$ & 2500 & 0.342 \\
\hline Poon [4] & $\begin{array}{l}p-\mathrm{Hf}_{0.3} \mathrm{Zr}_{0.7} \mathrm{CoSn}_{0.3} \mathrm{Sb}_{0.7} \\
n-\mathrm{Hf}_{0.6} \mathrm{Zr}_{0.4} \mathrm{NiSn}_{0.995} \mathrm{Sb}_{0.005}\end{array}$ & 704 & 2 legs & 423 & - \\
\hline $\begin{array}{c}\text { Sascha } \\
{[40]}\end{array}$ & $n-\mathrm{Ti}_{0.33} \mathrm{Zr}_{0.33} \mathrm{Hf}_{0.33} \mathrm{NiSn}$ & 565 & $\begin{array}{l}\text { 4-times } \\
2 \times 2 \times 4\end{array}$ & 44 & 0.275 \\
\hline This work & $\begin{array}{c}\mathrm{Hf}_{0.5} \mathrm{Zr}_{0.5} \mathrm{CoSn}_{0.2} \mathrm{Sb}_{0.8} / \mathrm{Bi}_{0.6} \mathrm{Sb}_{1.4} \mathrm{~T} \\
{ }_{n-\mathrm{Ti}_{0.6} \mathrm{Hf}_{0.4} \mathrm{NiSn}_{3} / \mathrm{Bi}_{2} \mathrm{Te}_{3}}\end{array}$ & 550 & $4 \times 4 \times 8$ & 49.2 & 0.3 \\
\hline
\end{tabular}

The stability of the segmented legs, evaluated by recording the change of thermoelectric outputs during several thermal cycles, is presented in Fig. 7 . After the $6^{\text {th }}$ cycle, the maximum voltage and power density of the $p$-type segmented leg decreased by $4.8 \%$ and $5.5 \%$, respectively compared with those obtained from the first cycle. As for the $n$-type segmented leg, the resulted maximum power density reduced by $5.4 \%$ after the $6^{\text {th }}$ cycle, and the highest voltage dropped by $3.9 \%$. The 
degradation of the output thermoelectric performance can be attributed to several possible reasons. The first reason could be the expansion of the interlayer between BiTe and $\mathrm{Ag}_{10} \mathrm{Sn}$, as observed from the microstructural analysis (see Fig. 2e, 2f, 2l, and 2k). As for the p-type leg, we observe shown more porosity of the solder layer probably due to diffusion of Sn into BiTe, which has also been observed in Ref. [29,33] and could influence the generated current (Fig. 2a and 2b). The measured contact resistance showed an increase at temperature approaching $525 \mathrm{~K}$ (Fig. 4). The second reason may be due to the increase of total TE leg resistance by the surface oxidation of the TE materials in the testing environment (air) and the sublimation of highly volatile elements, especially $\mathrm{Sb}$ in $\mathrm{HH}$ and BiTe [48,49]. The reduction of the maximum output voltage might result from the increase in thermal contact resistance between the TE elements and the alumina substrate during cycling. In addition, the effect of uneven deformation of alumina ceramic substrate as a result of high thermal gradient in the joining direction (which is known as Mayer-Marschall effect) also increases the thermal contact resistance of the tested TE leg [16].
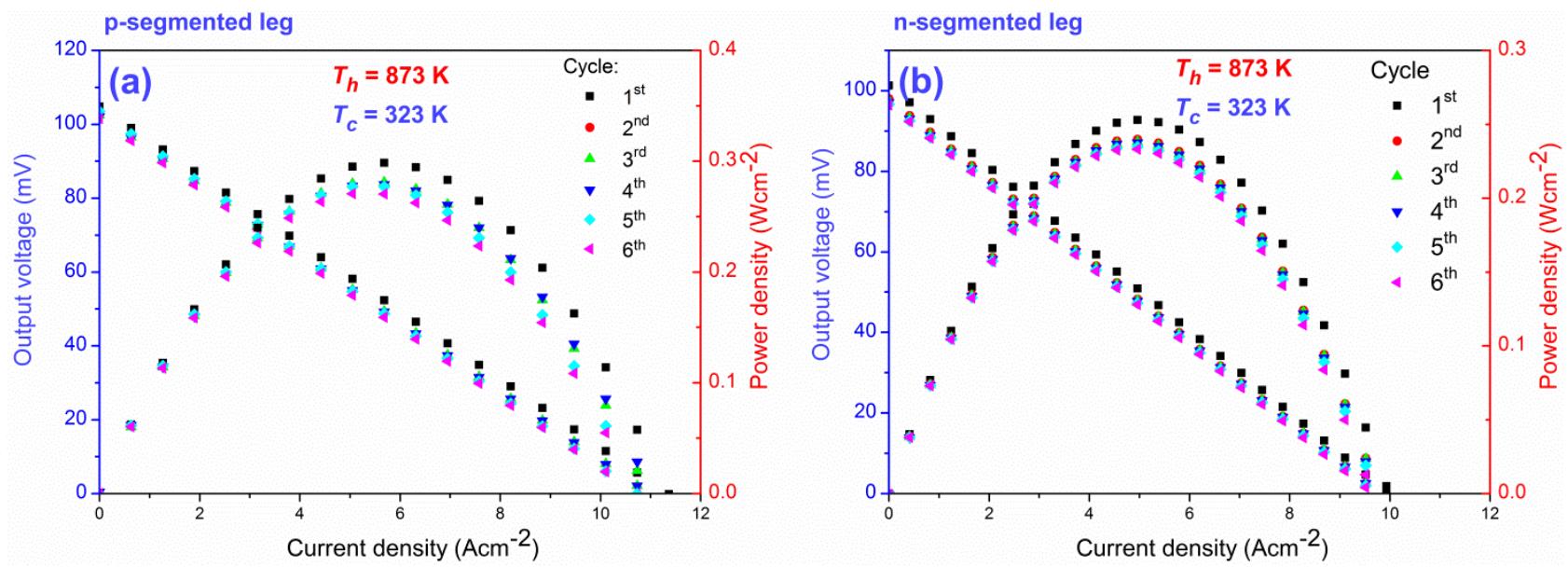

Fig. 7. Stability test of obtained segmented $p$-type segmented leg (a) and $n$-type segmented leg (b).

\section{Conclusion}

We have successfully segmented $p$ - and $n$-type BiTe and HH using a two-step fast hot pressing process and subsequently characterized the segmented legs. Microstructural and chemical elements analyses of the joint interfaces showed good contact and no sign of cracks at the joining between the materials. The diffusion of tin from the solder alloy into BiTe was observed with a penetration depth of $10 \mu \mathrm{m}$. Regardless, thermopower microprobe scanning in the vicinity of the joining interface showed no detrimental change of the Seebeck coefficient of the BiTe and $\mathrm{HH}$ of the segmented leg after joining, at least within the scale of $50 \mu \mathrm{m}$. The area specific contact resistance of the $p$-type $\mathrm{BiTe} / \mathrm{Ag}_{10} \mathrm{Sn} / \mathrm{Ag} / \mathrm{HH}$ structure was measured to be $50 \mu \Omega \cdot \mathrm{cm}^{2}$ at room temperature 
and increased to $75 \mu \Omega \cdot \mathrm{cm}^{2}$ at $523 \mathrm{~K}$. For the $n$-type leg, the contact resistance was found to be 50 $\mu \Omega \cdot \mathrm{cm}^{2}$ at room temperature and slightly decreased to $35 \mu \Omega \cdot \mathrm{cm}^{2}$ at $523 \mathrm{~K}$. The electrical resistivity and thermopower of the segmented legs were in good agreement with calculation with the exception of the Seebeck coefficient of the $p$-type segmented leg which was twice the calculated value due to a geometric measurement error inherent with the sample. The thermoelectric output tests in air environment of $p$-type segmented leg shows a maximum power density of $0.3 \mathrm{~W} \cdot \mathrm{cm}^{-2}$ under a temperature gradient of $550 \mathrm{~K}$. For the $n$-type segmented leg, the power density was $0.25 \mathrm{~W} \cdot \mathrm{cm}^{-2}$. After 6 thermal cycles with a hot-side temperature of $873 \mathrm{~K}$, the performance decreased by $5.5 \%$ and $5.4 \%$ for the $p$-type leg and $n$-type leg, respectively. The introduced process to join $\mathrm{HH}$ and BiTe is therefore promising for the development of a segmented thermoelectric generator.

\section{Acknowledgements}

The authors acknowledge the support from Copenhagen Cleantech Cluster for the research work (in Project 48062 $\mathrm{X}-\mathrm{CCC}$ ) and the Programme Commission on Energy and Environment (EnMi), which is part of the Danish Council for Strategic Research (Contract No. 10-093971), for sponsoring the research of the OTE-Power Project. We thank Professor Bo Brummerstedt Iversen for providing access to the potentional Seebeck microprobe Panco, which is sponsored by the Danish National Research Foundation (DNRF93).

\section{Appendix}

Table II. Chemical composition of interdiffusion layer between BiTe and solder alloy $\mathrm{Ag}_{10} \mathrm{Sn}$

\begin{tabular}{cllllll}
\hline Fig. 2 & \multicolumn{1}{c}{ Point } & \multicolumn{5}{c}{ Element composition (at.\%) } \\
\cline { 3 - 7 } & & $\mathrm{Bi}$ & $\mathrm{Te}$ & $\mathrm{Sb} / \mathrm{Se}$ & $\mathrm{Ag}$ & $\mathrm{Sn}$ \\
\hline \multirow{3}{*}{$\mathrm{f}$} & (1) $n$-type BiTe part & 37.2 & 49.5 & $3.5 / 2.9$ & 2.2 & 4.9 \\
& (2) Inter alloy 1 & 35.5 & 53.5 & $3.9 / 1.8$ & 0.3 & 5 \\
& (3) Inter alloy 2 & 2.8 & 0 & $5.3 / 0$ & 14.2 & 77.7 \\
& (4) Inter alloy 3 & 0.8 & 0 & $2.7 / 0.2$ & 66 & 30.4 \\
& & & & & & \\
b & (1) p-type BiTe part & 6.9 & 47.6 & $30.3 / 0.3$ & 7.6 & 7.3 \\
& (2) Inter alloy 1 & 2.1 & 35.8 & $15.9 / 0$ & 3.3 & 43.1 \\
& (3) Inter alloy 2 & 0.5 & 0.4 & $1.44 / 0$ & 64.6 & 33.1 \\
& (4) Inter alloy 3 & 4 & 0 & $12.8 / 0.6$ & 6.1 & 76.5
\end{tabular}

\section{References}

[1] D. M. Rowe, Thermoelectrics Handbook: Macro to Nano (Taylor and Franics Group, 2006).

[2] W. Liu, Q. Jie, H. S. Kim, and Z. Ren, Acta Materialia 87, 357 (2015).

[3] K. K. M. Mikami, and S. Tanaka, Mater. Trans. 52, 1546 (2011).

[4] S. J. W. Poon, D.; Zhu, S.; Xie, W.J.; Tritt, T.M.; Thomas, P.; Venkatasubramanian, R., J. Mater. Res. 26, 2795 (2011). 
[5] H. Scherrer, in CRC Handbook of Thermoelectrics, ed. D.M. Rowe (CRC Press, 2006), p. 211.

[6] H. J. Goldsmid, Springer series in Materials Science 3 (2001).

[7] N. V. Nong, L. Han, L. T. Hung, H. N. Pham, S. H. Spangsdorf, A. Roch, L. Stepien, and N. Pryds, in Proceeding of International conference on thermoelectrics (2015).

[8] N. V. Nong, L. T. Hung, H. Li, R. Bjørk, P. H. Ngan, T. C. Holgate, B. Balke, G. J. Snyder, S. Linderoth, N. Pryds, Energy Technol. 3, 1143 (2015).

[9] T. C. Holgate, H. Li, N. Wu, E. D. Bøjesen, M. Christensen, B. B. Iversen, N. V. Nong, N. Pryds, J. Alloys. Compd. 582, 827 (2014).

[10] L. H. T. H. Le, E. Stamate, H. N. Pham, B. Balke, S. Linderoth, N. Van Nong, and N. Pryds, in MRS Fall Meeting \& Exhibit, Boston, MA, 2013).

[11] R. Bjørk, J. Electron. Mater. 44, 2869 (2015).

[12] D. G. Zhao, H. Geng, and L. Chen, Int. J. Appl. Ceram. Technol. 9, 4, 733 (2012).

[13] X. Y. L. D. G. Zhao, Y. H. Cai, W. Jiang, and L. D. Chen, Mater. Sci. Forum 631, 313 (2009).

[14] D.E. Wesolowski, R.S. Goeke, A.M. Morales, S.H. Goods, P.A. Sharma, M.P. Saavedra, K.R. Reyes-Gil, W.C.G. Neel, N.Y.C. Yang, and C.A. Apblett, J. Mater. Res 27, 1149 (2012).

[15] M. Kambe, T. Jinushi, and Z. Ishijima, J. Electron. Mater. 43, 1959 (2013).

[16] M. Zebarjadi, K. Esfarjani, M. S. Dresselhaus, Z. F. Ren, and G. Chen, Energy Environ. Sci. 5, 5147 (2012).

[17] J. J. Shen, S. N. Zhang, S. H. Yang, Z. Z. Yin, T. J. Zhu, and X. B. Zhao, J. Alloys Compd. 509, 161 (2011).

[18] T.-S. Kim and B.-S. Chun, J. Alloys Compd. 437, 225 (2007).

[19] E. Maciá, in Thermoelectric Materials: Advances and Applications, Pan Stanford (2015), p.340.

[20] T. N. S. Hirono, M. Okamura, Patent WO2006067986 A1 (2007).

[21] M. S. F.-D. Börner, B. Feng, W. Lippmann, H.-P. Martin, A. Michaelis, and A. Hurtado, J. Mater. Res. 29, 1771 (2014).

[22] E. J. T. J. J. D’Angelo, F. Ren, B. D. Hall, E. Case, H. Schock, M. Kanatzidis, D. Y. Chung, and T. P. Hogan, MRS Online Proc. Libr. 1044 (2007).

[23] S. LeBlanc, Sustain. Mater. Technol. 1, 26 (2014).

[24] L. M. Pavlova, Y. I. Shtern, and R. E. Mironov, High Temperature 49, 369 (2011).

[25] K. N. R. Taylor, British J. Appl. Phys. 12 (1958).

[26] S. Hirono, T. Naba and M. Okamura, in Patent EP1835551A1 (2007).

[27] W. Brostow, T. Datashvili, H. E. Hagg Lobland, T. Hilbig, L. Su, C. Vinado, and J. White, J. Mater. Research 27, 2930 (2012).

[28] S.-W. Chen, C.-C. Chen, W. Gierlotka, A.-R. Zi, P.-Y. Chen, and H.-J. Wu, J. Electron. Mater. 37, 992 (2008). 
[29] Y. C. Lan, D. Z. Wang, G. Chen, and Z. F. Ren, Appl. Phys. Lett. 92, 101910 (2008).

[30] R. Z. K. T. Wojciechowski, J. Leszczynski, P. Nieroda, M. Schmidt, R. Gajerski, and E. Aleksandrova, Proceeding of the $9^{\text {th }}$ European conference on Thermoelectrics, p.467 (2012).

[31] W. P. Lin, D. E. Wesolowski, and C. C. Lee, J. Mater. Sci.: Mater. Electron. 22, 1313 (2011).

[32] M. F. D. C. Valette, R. Voytovych, and N. Eustathopoulos, Scr. Mater. 52, 1 (2005).

[33] C. H. L. C. N. Liao, and W. J. Chen, Electrochem. Solid-State Lett. 10, 23 (2007).

[34] T. Y. Lin, C. N. Liao, and A. T. Wu, J. Electron. Mater. 41, 153 (2011).

[35] N. V. Nong, L. T. Hung; H. Li; P. H. Ngan, N. Pryds, in Proceeding of the $34^{\text {th }}$ International Conference on Thermoelectrics, Dresden, Germany, (2015).

[36] S. Fujita, K. Ito, in Quantum theory of Conducting Matter, (Springer New York, 2007). p. 195

[37] L. K. P. Fiflis, D. Andruczyk, D. Curreli, and D. N. Ruzic, J. Nucl. Mater. 438, 224 (2013).

[38] B. L. Q. Zhang, Y. Lan, K. Lukas, W. Liu, K. Esfarjani, C. Opeil, D. Broido, G. Chen, and Z. Ren, Proc. Natl. Acad. Sci. U. S. A. 110, 13261 (2013).

[39] D. Zhao, H. Geng, and X. Teng, J. Alloys. Compd. 517, 198 (2012).

[40] S. Populoh, O. Brunko, K. Gałązka, W. Xie, and A. Weidenkaff, Mater. 6, 1326 (2013).

[41] K. Arai, M. Matsubara, Y. Sawada, T. Sakamoto, T. Kineri, Y. Kogo, T. Iida, and K. Nishio, J. Electron. Mater. 41, 1771 (2012).

[42] H. O. O. Yamashita, S. Tomiyoshi, J. Mater. Scien. 39, 5653 (2004).

[43] W. A. Harrison, in Solid State Theory, (Dover Publications 2012).

[44] Y. Apertet, H. Ouerdane, C. Goupil, P. Lecoeur, Energ. Convers. Manag. 93, 160 (2015).

[45] J. de Boor, C. Gloanec, H. Kolb, R. Sottong, P. Ziolkowski, and E. Müller, J. Alloys Compd 632, 348 (2015).

[46] D. K. Aswal, R. Basu, and A. Singh, Energ. Conver. Manage. 114, 50 (2016).

[47] M. Mikami, K. Kobayashi, T. Kawada, K. Kubo, and N. Uchiyama, J. Electron. Mater 38, 1121 (2009).

[48] H. S. Kim, W. Liu and Z. Ren, Energ. Environ. Sci., 10, 69 (2017).

[49] H. H. S. a. M. S. El-Genk, AIP Conf. Proc. 608, 998 (2002). 


\section{Figure captions}

Fig.1. Thermoelectric properties of BiTe and HH in $p$-type segmented leg (a-d) and $n$-type segmented leg (e-h).

Fig. 2. SEM images and EDS chemical analysis at the joint interface of $p$-type (a-d), $n$-type (e-h) segmented leg before heat treatment and (i-m) $n$-type segmented leg after heat treatment. After heat treatment, the $p$ type segmented leg delaminated, so no further microstructural analysis had been conducted.

Fig. 3. Scanning Seebeck analysis at the joint interface of $p$-type (a) and $n$-type (b, c) segmented legs

Fig. 4. Temperature - dependence of area specific contact resistance of the $p$ - and $n$-type segmented legs

Fig. 5. Resistivity and Seebeck coefficient of the $p$-type (a, b) and $n$-type segmented leg (c, d) measured by ZEM 3.

Fig. 6. Output voltage vs. current density characteristics of obtained $p$-type (a) and $n$-type segmented leg (b).

Fig. 7. Stability test of obtained $p$-type (a) and $n$-type segmented leg (b). 


\author{
Joining of half-Heusler and bismuth tellurides for segmented thermoelectric generators \\ Pham Hoang Ngan*, Li Han and Dennis Valbjфrn Christensen \\ Department of Energy Conversion and Storage, Technical University of Denmark, Roskilde, Denmark \\ *Email:ngan.pham@dlr.de
}

\begin{abstract}
Segmented generators where the $p$ - or $n$-type legs are formed by joining materials in series enables each material to operate in their most efficient temperature range. Here, we have fabricated and characterized segmented thermoelectric $p$ - and $n$-type legs based on bismuth tellurides and halfHeusler alloys $p$-type $\mathrm{Hf}_{0.5} \mathrm{Zr}_{0.5} \mathrm{CoSn}_{0.2} \mathrm{Sb}_{0.8}$ and $n$-type $\mathrm{Ti}_{0.6} \mathrm{Hf}_{0.4} \mathrm{NiSn}$. A two-step process was introduced to join the half-Heusler to the bismuth tellurides to form a segmented structure which was then characterized for its thermoelectric and structural properties. The output power generation was characterized under various hot side temperatures up to $873 \mathrm{~K}$ with the cold side fixed at 323 $\mathrm{K}$. The stability of the joints was also investigated under heat treatment and thermal cycling. Under working temperatures from 323 to $873 \mathrm{~K}$, the obtained $p$-type segmented legs could deliver a power density of $0.3 \mathrm{~W} \cdot \mathrm{cm}^{-2}$ and maximum voltage of $115 \mathrm{mV}$. With the same condition, the power density and the maximum voltage generated by $n$ - type segmented leg were $0.25 \mathrm{~W} \cdot \mathrm{cm}^{-2}$ and 102 $\mathrm{mV}$. The area-specific contact resistance of the $p$ - and $n$ - type legs were $50 \mu \Omega \cdot \mathrm{cm}^{2}$ and $35 \mu \Omega \cdot \mathrm{cm}^{2}$, respectively. The output performance of each leg was $\sim 95 \%$ after 6 cycles from $323 \mathrm{~K}$ to $873 \mathrm{~K}$.
\end{abstract}

Key words: Segmented thermoelectric generator, thermoelectric joining, bismuth telluride, halfHeusler

\title{
1 Introduction
}

Although thermoelectric (TE) power generation has many advantages, its conversion efficiency so far is still rather low: less than $10 \%$. One example is thermoelectric generators (TEG) composed of half-Heusler (HH) alloys that are very competitive materials suitable for medium-high temperature range up to about $873 \mathrm{~K}[1,2]$. A unicouple composed of the $p$-type $\mathrm{Fe}_{2} \mathrm{VAl}_{0.9} \mathrm{Si}_{0.1}$ and $n$-type $\mathrm{Fe}_{2} \mathrm{~V}_{0.9} \mathrm{Ti}_{0.1} \mathrm{Al}$ Heusler alloys has an efficiency of $1.4 \%$ with hot side temperature of $573 \mathrm{~K}$ and cold side temperature of $293 \mathrm{~K}$ [3]. Recently, unicouple of $\mathrm{Hf}_{0.3} \mathrm{Zr}_{0.7} \mathrm{CoSn}_{0.3} \mathrm{Sb}_{0.7}$ and $\mathrm{Hf}_{0.6} \mathrm{Zr}_{0.4} \mathrm{NiSn}_{0.995} \mathrm{Sb}_{0.005}$ have been found to possesses the conversion efficiency of $8.7 \%$ with $T_{h}=$ $970 \mathrm{~K}$ and temperature gradient of $948 \mathrm{~K}$ [4]. Segmentation of HH with bismuth telluride (BiTe), the dominant material at the low temperature range up to $473 \mathrm{~K}$ [5-7] is predicted from numerical modeling to improve the thermal conversion efficiency of TEG [5,8-10]. In particular, calculations predicted [6] that a segmented leg of BiTe with $\mathrm{HH}$ could reach a maximum efficiency of more than 
$10 \%$ at hot side and cold side temperatures of $900 \mathrm{~K}$ and $300 \mathrm{~K}$, respectively. Therefore, this work is aimed at segmenting these two materials and pave the way to develop high efficiency segmented TEG.

Since different TE materials often have different physical and chemical characteristics, joining these materials is considered to be the most challenging part in fabricating segmented TEGs $[5,10,11]$. The joining process requires strong adhesion, good chemical stability, and low contact resistance between the materials [10-13]. Joining $\mathrm{HH}$ and BiTe is no exception and poses major challenges. BiTe is suitable at temperatures below $523 \mathrm{~K}$ and deteriorates above $773 \mathrm{~K}$ due to the degradation of the material [7,14-18]. HH, however, is composed of thermally stable materials with melting points exceeding $1773 \mathrm{~K}$, depending on composition. The low wettability, however, results in a low capability to form bonds with other materials $[19,20]$. According to D'Angelo and Börner et al. [21,22], in order to directly join two different materials, the temperature at their interface should be elevated to the range from 50 to $80 \%$ of the lowest melting point. Thus, $\mathrm{HH}$ and BiTe cannot be joined directly together due to their large difference in melting temperature. In this work, segmentations of $\mathrm{BiTe}$ (n-type $\mathrm{Bi}_{2} \mathrm{Te}_{3}$ and $p$-type $\mathrm{Bi}_{0.6} \mathrm{Sb}_{1.4} \mathrm{Te}_{3}$ ) with $\mathrm{HH}$ materials (n-type $\mathrm{Ti}_{0.6} \mathrm{Hf}_{0.4} \mathrm{NiSn}$ and $p$-type $\mathrm{Hf}_{0.5} \mathrm{Zr}_{0.5} \mathrm{CoSn}_{0.2} \mathrm{Sb}_{0.8}$ ) were made using a two-step process. The obtained segmented legs were then investigated in detail.

\section{Experimental}

\subsection{Material preparation}

$p$ - and $n$-type $\mathrm{HH}$ thermoelectric alloys with nominal compositions $\mathrm{Hf}_{0.5} \mathrm{Zr}_{0.5} \mathrm{CoSn}_{0.2} \mathrm{Sb}_{0.8}$ and $\mathrm{Ti}_{0.6} \mathrm{Hf}_{0.4} \mathrm{NiSn}$, respectively, were prepared by arc melting the stoichiometric mixture of the pure elements. The arc-melted ingots were then ball milled (Planetary ball mill PM 100) into fine powder with particle size distribution ranging from 1 to $10 \mu \mathrm{m}$. The powders were then consolidated into bulk samples by spark plasma sintering (SPS 515S). The sintering was done at a pressure of 50 $\mathrm{MPa}$ and a temperature of $1200{ }^{\circ} \mathrm{C}$ for $p$-type and at $1050{ }^{\circ} \mathrm{C}$ for $n$-type with the ramping rate of 50 ${ }^{\circ} \mathrm{C}$ per min for both types. The sintering processes took $30 \mathrm{~min}$ for each sample. BiTe ingots of $p$ type $\mathrm{Bi}_{0.6} \mathrm{Sb}_{1.4} \mathrm{Te}_{3}$ and $n$-type $\mathrm{Bi}_{2} \mathrm{Te}_{3}$ were purchased commercially and their TE properties were measured.

The electrical resistivity and Seebeck coefficient of the materials were measured using ZEM 3 (ULVAC) with measurement uncertainties of 3-5\% for the electrical resistivity and 5-7\% for the Seebeck coefficient. The thermal conductivity $(\kappa)$ was calculated from the thermal diffusivity $(\alpha)$, the mass density $(D)$ and the specific heat capacity $\left(C_{p}\right)$ according to the equation $\kappa=\alpha D C_{p}[1]$ The thermal diffusivity was obtained by the laser flash method (Netzsch LFA-457), the mass densities of the samples were measured by Archimedes' method using water with surfactant, and the 
specific heat capacity was measured using a differential scanning calorimeter (Netzsch DSC 404C). The uncertainty of the thermal conductivity is $7-10 \%$.

\subsection{Segmentation of BiTe and HH}

From the obtained ingots, BiTe and $\mathrm{HH}$ were cut into rectangular pieces and assembled into segmented TE leg with a cross sectional area of $4 \times 4 \mathrm{~mm}^{2}$ and a total length of $8 \mathrm{~mm}$. The length of $8 \mathrm{~mm}$ was chosen to be suitable for further characterization steps and to maintain the temperature gradient of $843 \mathrm{~K}$. The surfaces of the samples were polished with sandpaper and then cleaned before the joining process. Polished samples of $p$ - and $n$-type $\mathrm{HH}$ were ultrasonically treated in acetone, isopropanol and de-ionized water, followed by carbon dioxide cleaning.

$\mathrm{HH}$ alloys and BiTe were joined using a fast hot pressing technique with details described in reference [9]. Much effort has been made to join $\mathrm{HH}$ with the BiTe in a single-step process [ $\leftarrow$ remove second hyphen] by various joining materials chosen to minimize mismatch of thermal expansion coefficients which is a well-known source of delamination and cracking at high temperature [23]. The thermal expansion coefficient (CTE) of BiTe is $\sim 16.4 \mu \mathrm{K}^{-1}[24,25]$ and that of $\mathrm{HH}$ is $\sim 13 \mu \mathrm{K}^{-1}$ [9]. Thus, different solder alloys were used such as, $\mathrm{Ag}_{10} \mathrm{Sn}(\mathrm{Ag} 10 \%$ wt and $\mathrm{Sn}$ $90 \% \mathrm{wt})\left(\mathrm{CTE}=22 \mu \mathrm{K}^{-1}\right)$ or $\mathrm{Cu}\left(\mathrm{CTE}=16.5 \mu \mathrm{K}^{-1}\right)$, Ni $\left(\mathrm{CTE}=13 \mu \mathrm{K}^{-1}\right)$, and $\mathrm{Al}\left(\mathrm{CTE}=22 \mu \mathrm{K}^{-1}\right)$. However, the joining was not successful mainly due to the poor wettability of half-Heusler with the molten solders. The problem was also encountered in Ref. [20,26]. We therefore developed a twostep procedure to join $\mathrm{HH}$ and BiTe. First, $\mathrm{HH}$ was joined with $\mathrm{Ag}$ by hot pressing at $1053 \mathrm{~K}$ under a pressure of $40 \mathrm{MPa}$ in vacuum following the joining process described in [9]. Following the coating of $\mathrm{Ag}$, the $\mathrm{Ag}$ surface of the joined $\mathrm{HH} / \mathrm{Ag}$ was cleaned with acetone and ethanol. A $0.3 \mu \mathrm{m}$ thick foil of $\mathrm{Ag}_{10} \mathrm{Sn}$ solder alloy was placed on top of the cleaned $\mathrm{Ag}$ surface and joined with the BiTe segment. The TE leg was placed into a spark plasma sintering (SPS) chamber and processed at $493 \mathrm{~K}$, under a pressure of $30 \mathrm{MPa}$ in vacuum. These joining conditions were optimized based on the melting temperature of the solder alloy and the maximum load that BiTe can maintain without cracking. A custom-made alumina structure was used to prevent the current in the SPS from flowing through the TE materials since the high current density would cause local superheating and current effects at interfaces, thus affect the TE properties of the materials [2].

\subsection{Characterization of the as-joined interface.}

The obtained segmented sample was cut into different pieces perpendicular to the direction of the joining interface to analyze the microstructural and electrical properties across the interface. The microstructures and chemical distributions of elements at the joint were analyzed by scanning electron microscopy (SEM) and energy dispersive X-ray spectroscopy (EDS) (Zeiss Supra-35). The thermopower of adjacent materials at the joined interfaces were scanned by a Seebeck scanning microprobe (Panco) with scanning probe resolution of $50 \mu \mathrm{m}$ as described elsewhere [9]. The 
contact resistances of the joined samples were measured (Fig. 1b) using a 4-probe scanning method described also in [9] with measurement uncertainty of 1-3\%, excluding geometric uncertainty. Characterizations of the obtained $\mathrm{BiTe} / \mathrm{HH}$ were carried out with increasing temperature from $50 \mathrm{~K}$ to $473 \mathrm{~K}$ due to the melting limitation of solder $\mathrm{Ag}_{10} \mathrm{Sn}$. The stability of the joint materials was studied at $473 \mathrm{~K}$ for $48 \mathrm{~h}$ in a flowing nitrogen environment to minimize a possible oxidation of BiTe and sublimation of tellurium and antimony (in p-type BiTe) [2,27]. Characterization of the materials was done before and after the heat treatment.

\subsection{Characterization of $\boldsymbol{p}$ - and $\boldsymbol{n}$ - BiTe/HH segmented legs}

The electrical resistivity and Seebeck coefficient of the segmented leg, including the interface layer have been measured by using ZEM 3 (ULVAC). Finally, the voltage-current characteristics of the legs were measured at a constant temperature span with a measurement uncertainty of $1.2 \%$. Details of the test system is described in [8].

\section{Results and discussion}

\subsection{Thermoelectric properties of bismuth tellurides and half-Heusler materials}

The electrical resistivity $(\rho)$, Seebeck coefficient $(S)$ and thermal conductivity $(\kappa)$ as a function of temperature for BiTe and $\mathrm{HH} p$ - and $n$-type materials are shown in Fig. 1 . Both $p$ - and $n$-type BiTe show a metallic-like behavior of the electrical resistivity, similar to that of $p$-type $\mathrm{HH}$. As for $n$-type $\mathrm{HH}$, the electrical resistivity exhibits a semiconductor-like behavior. The absolute values of the Seebeck coefficient of both types of BiTe peaked at $\sim 220 \mu \mathrm{V} \cdot \mathrm{K}^{-1}$ at $373 \mathrm{~K}$ and $423 \mathrm{~K}$ for $n$ - and $p$-type, respectively. The Seebeck coefficient of $p$-type $\mathrm{HH}$ increased over the whole measured temperature range to a maximum value of $220 \mu \mathrm{V} \cdot \mathrm{K}^{-1}$ at $873 \mathrm{~K}$. Meanwhile, the Seebeck coefficient of $n$-type $\mathrm{HH}$ increased to a value of $260 \mu \mathrm{V} \cdot \mathrm{K}^{-1}$ at $623 \mathrm{~K}$ and then decreased upon raising the temperature, reaching a value of $190 \mu \mathrm{V} \cdot \mathrm{K}^{-1}$ at $873 \mathrm{~K}$ due to bi-polar conduction effect. By segmenting BiTe and $\mathrm{HH}$, the average $Z T$ of $p$ - and $n$-type segmented legs, calculated by averaging $z T$ across the temperature range $(300-873 \mathrm{~K})$, with $z T=S^{2} T / \rho \kappa[5]$ were 0.4 and 0.5 , respectively. 

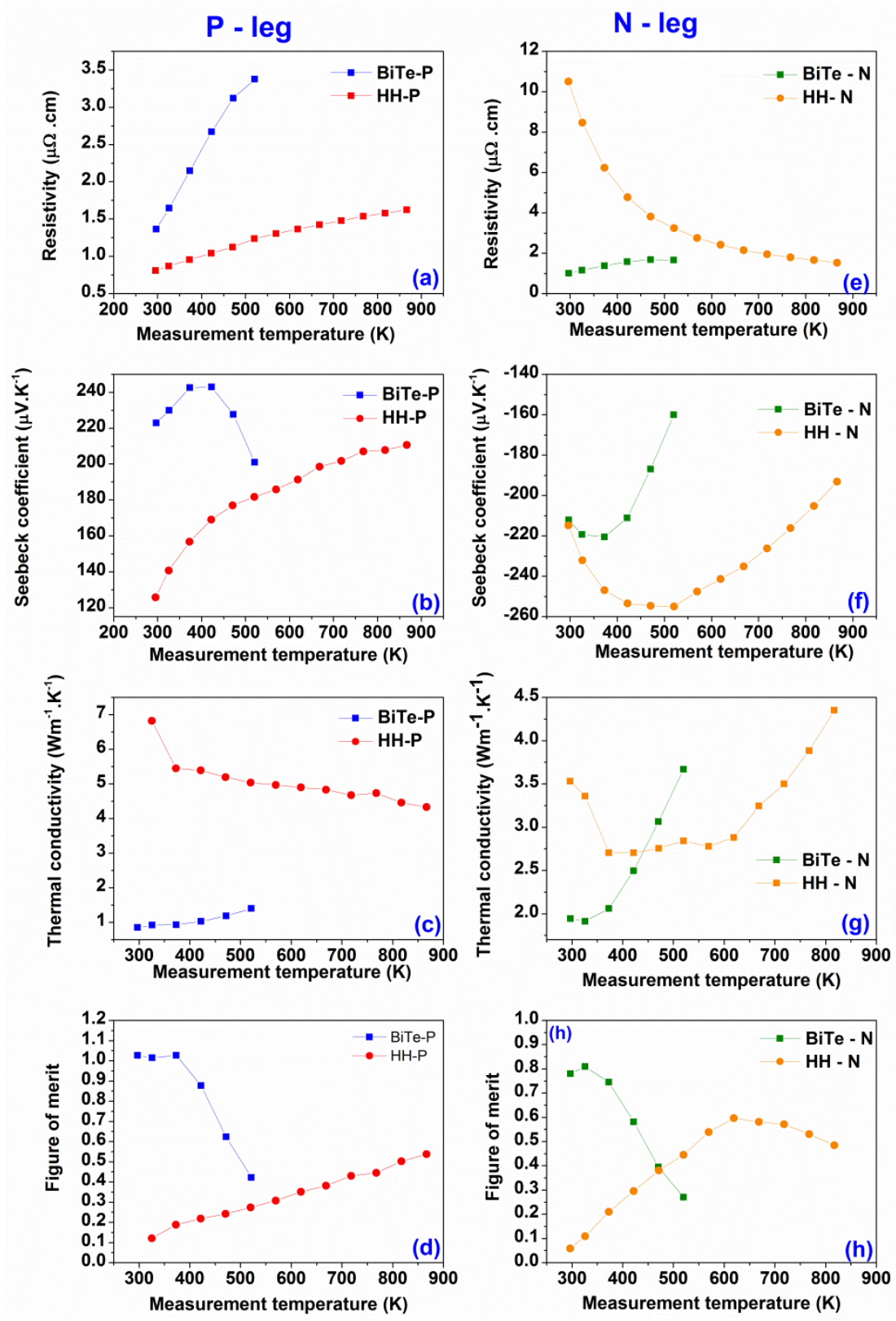

Fig.1. Thermoelectric properties of BiTe and HH in $p$-type (a-d) and $n$-type segmented leg (e-h).

\subsection{Interfacial microstructural and thermoelectric analyses}

Microstructure and chemical analysis at the interface of the $p$ - and the $n$-type segmented TE elements are shown in Fig. 2. For both the $p$ - and the $n$-type no sign of delamination and cracks between joining layers were observed. In both $p$ - and $n$-type cases, EDS analyses show that in the solder layer, there are regions of Sn- and Ag-rich phases: points (3) and (4) in Fig. 2(b) and 2(f). A small amount of $\mathrm{Sb}$ was also detected in the solder layer, which might be the consequence of diffusion from BiTe to form an interphase with $\mathrm{Sn}$ in the solder [28]. An intermediate region rich in Sn with thickness of $\sim 10 \mu \mathrm{m}$ formed towards the BiTe side, indicating the diffusion of Sn into BiTe, 
which was also observed in several other works [29-31]. The compositions of these interface regions were quantified in Table II (see Appendix).

After heat treatment, the development of the interdiffusion layer between BiTe and solder alloy $\mathrm{Ag}_{10} \mathrm{Sn}$ is observed in the $n$-type leg. The total thickness of the $\mathrm{Ag}_{10} \mathrm{Sn} /$ interdiffusion layers increased from $40 \mu \mathrm{m}$ to $60 \mu \mathrm{m}$ after heat treatment. EDS analysis of the interdiffusion layer showed that there is a tendency of Sn to diffuse into BiTe to form SnTe-rich phases [29]. After $48 \mathrm{~h}$ of heat treatment, the diffusion layer between BiTe and solder alloy expanded by $30 \mu \mathrm{m}$ (from 10 to $40 \mu \mathrm{m})$. The $p$-type segmented leg however, delaminated after the heat treatment. The delamination could be due to the fast diffusion of Sn into $p$-type BiTe that degraded the solder layer [33-35]. The interdiffusion layer between BiTe and $\mathrm{HH}$ became more visible after heat treatment (Fig. $2 \mathrm{f}$ and $2 \mathrm{k})$.

The Seebeck coefficient profiles of the joined interfaces for $p$ - and $n$-type segmented leg are shown in Fig. 3. The $\sim 200 \mu \mathrm{m}$ thickness of Ag filler corresponds well with the region with low Seebeck coefficients in the range of $0-10 \mu \mathrm{V} \cdot \mathrm{K}^{-1}$ on the scanned area. The intermediate region between $\mathrm{BiTe}$ and $\mathrm{Ag}_{10} \mathrm{Sn}$ solder was observed in the $p$-segmented leg. As reflected from the SEM and EDS analysis, this intermediate region is likely due to the newly formed diffusion layer composed of $(\mathrm{Sn}, \mathrm{Sb})$ and $(\mathrm{Sn}, \mathrm{Te})$-rich phases between BiTe and the solder. It can be interpreted from the Seebeck coefficient mapping results that this intermetallic layer has a thermopower of $\sim 110 \mu \mathrm{V} \cdot \mathrm{K}^{-1}$, which is lower than the $\sim 180 \mu \mathrm{V} \cdot \mathrm{K}^{-1}$ in BiTe. Towards the $\mathrm{HH}$ region, changes in thermopower of the TE material after joining were not observed. In the case of the $n$-type segmented leg, the Ag and solder layer between BiTe and $\mathrm{HH}$ after joining was measured to be $<20$ $\mu \mathrm{V} \cdot \mathrm{K}^{-1}$. This value corresponds well with the Seebeck coefficients of $\mathrm{Ag}\left(\sim 1.5 \mu \mathrm{V} \cdot \mathrm{K}^{-1}[36]\right)$, Sn ($\left.1.5 \mu \mathrm{V} \cdot \mathrm{K}^{-1}[37]\right)$ and $\operatorname{SnTe}\left(\sim 25 \mu \mathrm{V} \cdot \mathrm{K}^{-1}[38]\right)$, which were the main components observed from the EDS analysis. 

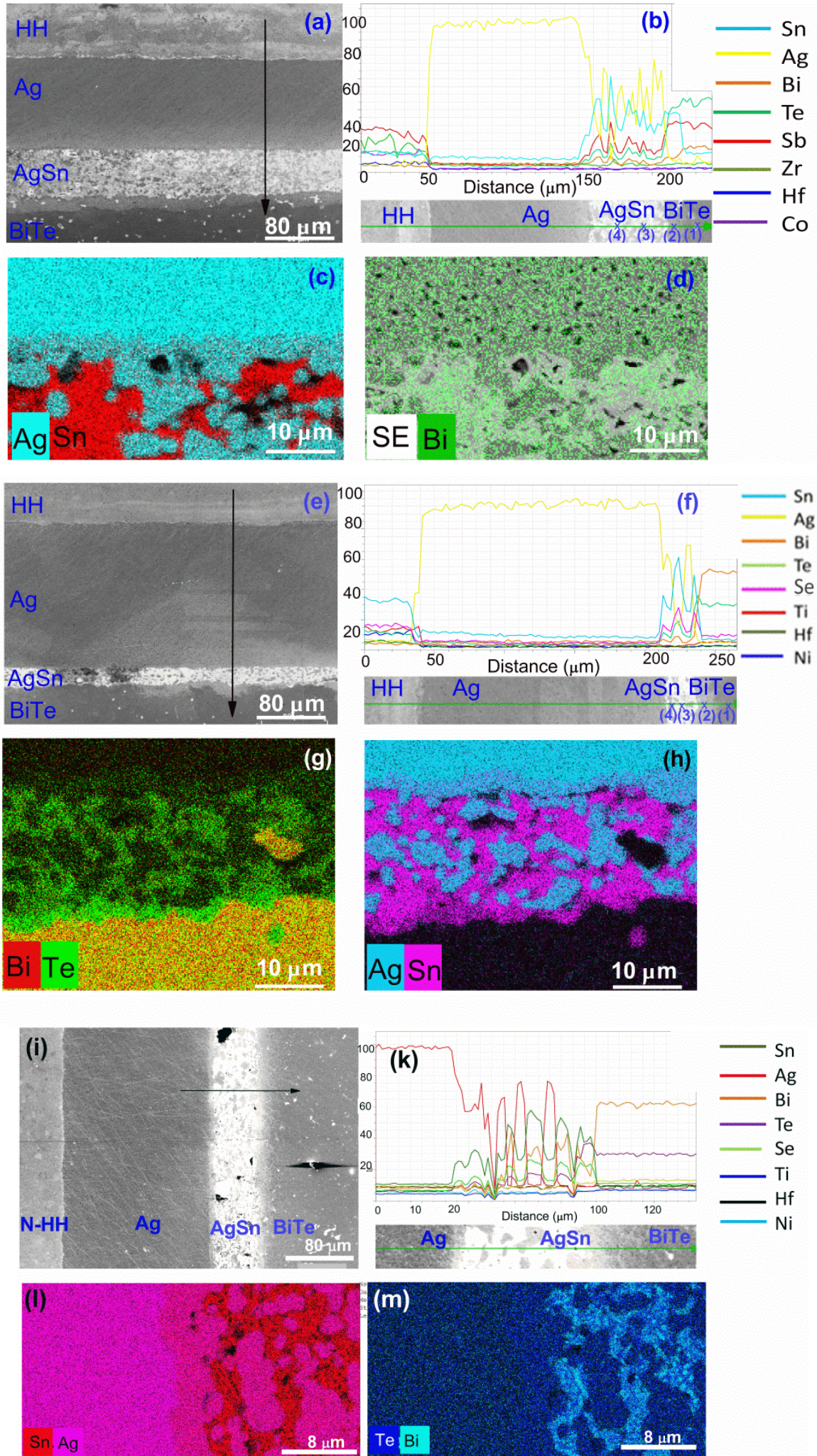

Fig. 2. SEM images and EDS chemical analysis at the joint interface of $p$-type (a-d), $n$-type (e-h) segmented leg before heat treatment and (i-m) $n$-type segmented leg after heat treatment. After heat treatment, the $p$-type segmented leg delaminated, so no further microstructural analysis was conducted. 

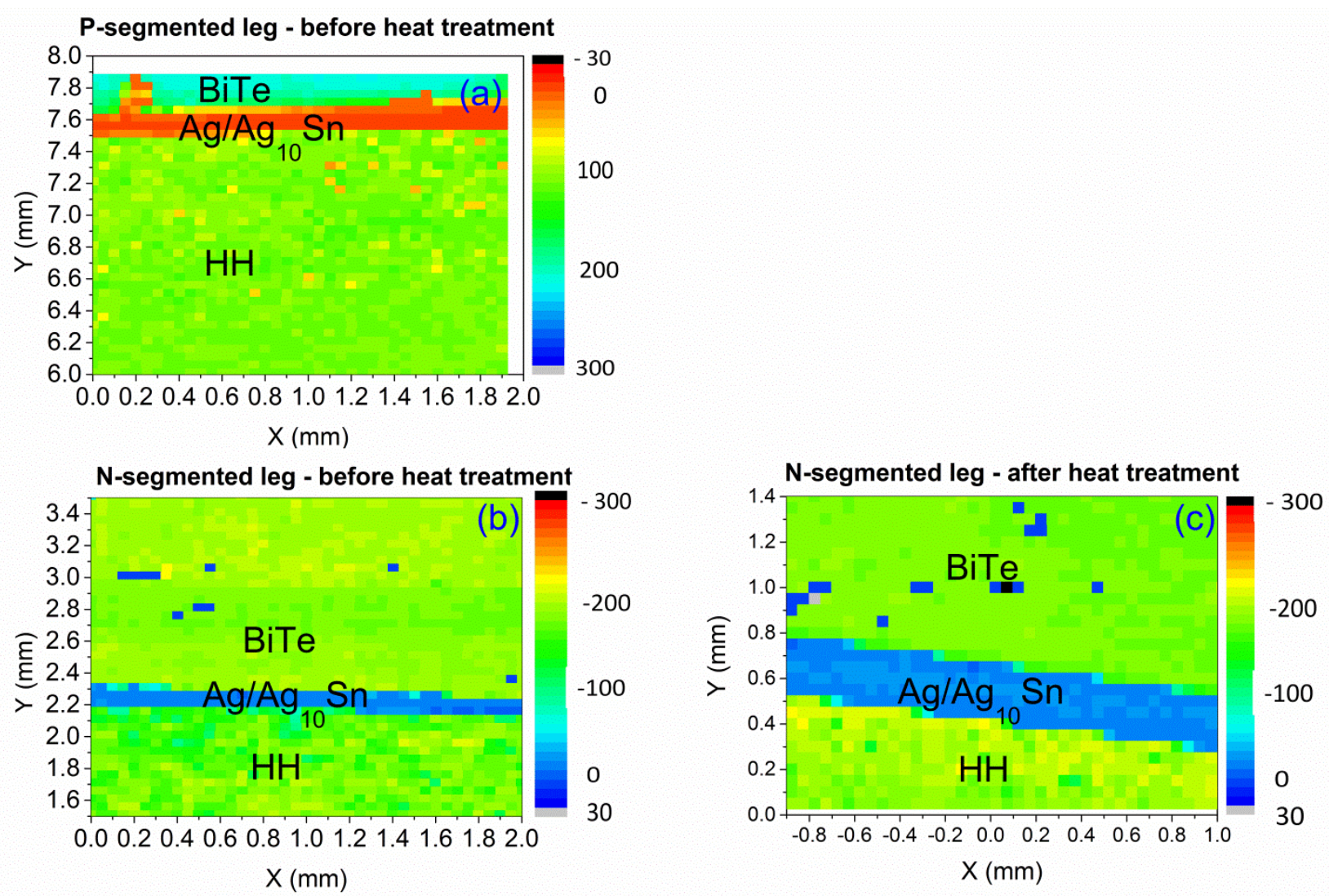

Fig. 3. Scanning Seebeck analysis at the joint interface of $p$-type (a) and $n$-type (b, c) segmented leg

\subsection{Electrical contact resistances}

One of the most critical features of a joined TE element is its area-specific contact resistance. At room temperature, the area-specific contact resistances of the obtained $p$ - and $n$ - type segmented elements are 50 and $40 \mu \Omega \cdot \mathrm{cm}^{2}$, respectively (Fig. 4). These values are competitive compared with other studies where contact resistances were below $100 \mu \Omega \cdot \mathrm{cm}^{2}[8,9,12,39-41]$. This overall specific contact resistance (denoted as $R_{c i}$ ) contains resistances of three interfaces: $\mathrm{HH} / \mathrm{Ag}$, $\mathrm{Ag} / \mathrm{Ag}_{10} \mathrm{Sn}$ and $\mathrm{Ag}_{10} \mathrm{Sn} / \mathrm{Bi}_{2} \mathrm{Te}_{3}$. Over the whole temperature range, the contact resistance of the $p$ type segmented leg was found to be higher than that of the $n$-type segmented leg, presumably due to the presence of SnTe in the interfacial layer between BiTe and $\mathrm{Ag}_{10} \mathrm{Sn}$ solder. SnTe is commonly used as $p$-type semiconductor because of its high Sn- vacancies characteristic, resulting in high concentrations of holes $[13,38]$. Thus, the $p$-type BiTe/SnTe contact is more likely to have higher contact resistance compared to the $n$-type BiTe/SnTe interface. Observation of high contact resistance for $p$-type TE material and metal interface have been studied and reported by Yamashita [42]. 


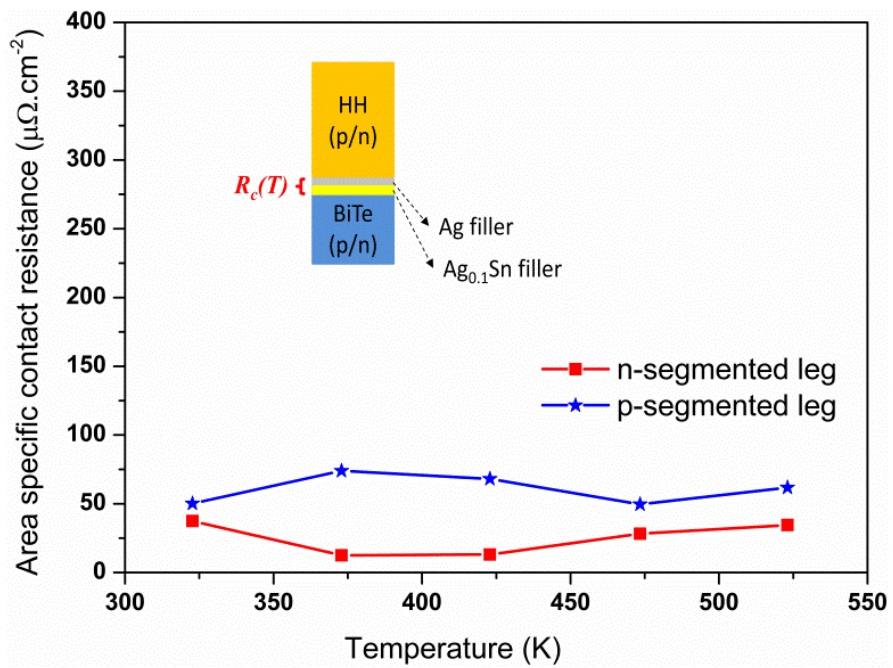

Fig. 4. Temperature-dependence of area specific contact resistance of the $p$ - and $n$-type segmented legs

\subsection{Thermoelectric characteristics of segmented legs}

Thermoelectric properties of the as-prepared segmented legs are shown in Fig. 5. The measured values were also compared with the results from calculation based on reference [44]. Details of the calculation are provided below. The calculation does not take into account any interfacial effects except for the electrical resistances. The electrical conductivity of the segmented legs can be calculated by Eq. 1 below:

$$
\frac{\rho_{\text {seg }} l_{\text {total }}}{A}=\frac{\rho_{\text {BiTe }} l_{\text {BiTe }}+\rho_{H H} l_{H H}+A S R C}{A}
$$

where $A$ is the cross sectional area of the segmented legs which is in this case similar both to $n$ - and $p$-type legs, $A S R c$ is the measured area specific contact resistance, $l_{B i T e}, l_{\text {interlayer }}$, and $l_{H H}$ are the lengths of the BiTe material, interlayer and $\mathrm{HH}$ material, respectively, giving a total length of $l_{\text {total }}=$ $l_{B i T e}+l_{\text {interlayer }}+l_{H H}$. The factors $\rho_{B i T e}, \rho_{H H}$ are the resistivities of the $p / n$-type BiTe and the $p / n$-type $\mathrm{HH}$ from (Fig. 1a, 1e), allowing $\rho_{\text {seg }}$ of both $p$ - and $n$ - type materials to be calculated.

The measured and the calculated $\rho_{\text {seg }}$ of both $p$ - and $n$ - segmented legs (denoted as $\rho_{p \text {-seg }}$ and $\rho_{n \text { - }}$ seg, respectively) are in good agreement with each other (Fig. 5a and 5c). As it can be seen from Fig. $5 \mathrm{c}$, for the $n$-type segmented leg, the $\rho_{n \text {-seg }}$ shows a semiconductor behavior with the value of $4 \mathrm{~m} \Omega \cdot \mathrm{cm}$ at $323 \mathrm{~K}$ and decreased to $0.2 \mathrm{~m} \Omega \cdot \mathrm{cm}$ at $473 \mathrm{~K}$. The $n$-type segmented leg, on the other hand, shows a metallic behavior: $\rho_{p \text {-seg }}$ increased from 0.8 to $1.4 \mathrm{~m} \Omega \cdot \mathrm{cm}$ as temperature increased from 323 to $473 \mathrm{~K}$ (see Fig. 5a). The measured values were slightly smaller than the calculated ones. It is possible that there is difference in the contact resistance measured by the different equipment. The source of variance is also due to the accurate thickness determination of the intermediate layer using SEM image [45]. All these factors could add up to the discrepancy between measurement and calculation. 
The thermopower of the segmented leg $\alpha_{\text {seg }}$ can be calculated from the intrinsic thermopower of the component materials using the following equation [44]:

$$
\alpha_{\text {seg }}=\frac{\Delta V}{\Delta T}=\frac{\kappa_{H H} \alpha_{B i T e}+\kappa_{B i T e} \alpha_{H H}}{\kappa_{H H}+\kappa_{B i T e}}
$$

where $\kappa_{B i T e}, \kappa_{H H}$ are the thermal conductivities of the BiTe and the HH (Fig. 1c, $1 \mathrm{~g}$ ) and $\alpha_{B i T e}, \alpha_{H H}$ are the Seebeck coefficients of the segmented materials (Fig. 1b, 1f).

The thermopower of $n$-type segmented leg obtained from the measurements are in good agreement with calculations as seen in Fig. $5 \mathrm{c}$. Below $373 \mathrm{~K}, \alpha_{n \text {-seg }}=220 \mu \mathrm{V} \cdot \mathrm{K}^{-1}$, which is slightly smaller than the calculated value of $240 \mu \mathrm{V} \cdot \mathrm{K}^{-1}$. The difference might originate from the uncertainty of the temperature measurement of the thermocouple probe. Another reason is the contribution of thermal contact resistances that needs further thermal contact resistance measurements to determine. The $p$-type segmented leg, however, had measured $\alpha_{p \text {-seg }}$ significantly higher than computed. Calculated $\alpha_{p \text {-seg }}$ was estimated to be from 150 to $180 \mu \mathrm{V} \cdot \mathrm{K}^{-1}$, while measurement showed values from 320 to $230 \mu \mathrm{V} \cdot \mathrm{K}^{-1}$ from 323 to $473 \mathrm{~K}$. This might be due to the geometry of the segmented leg determined to optimize thermoelectric output. For the $p$-type sample, the optimal performance was obtained when the BiTe-part should be only $0.6 \mathrm{~mm}$ thick (details of the calculation are not shown here), while the size of the ZEM3 probe is $0.5 \mathrm{~mm}$. As a consequence, the position of the probe in the measurement was too close to the joining interface and therefore strongly influenced the measured data. 

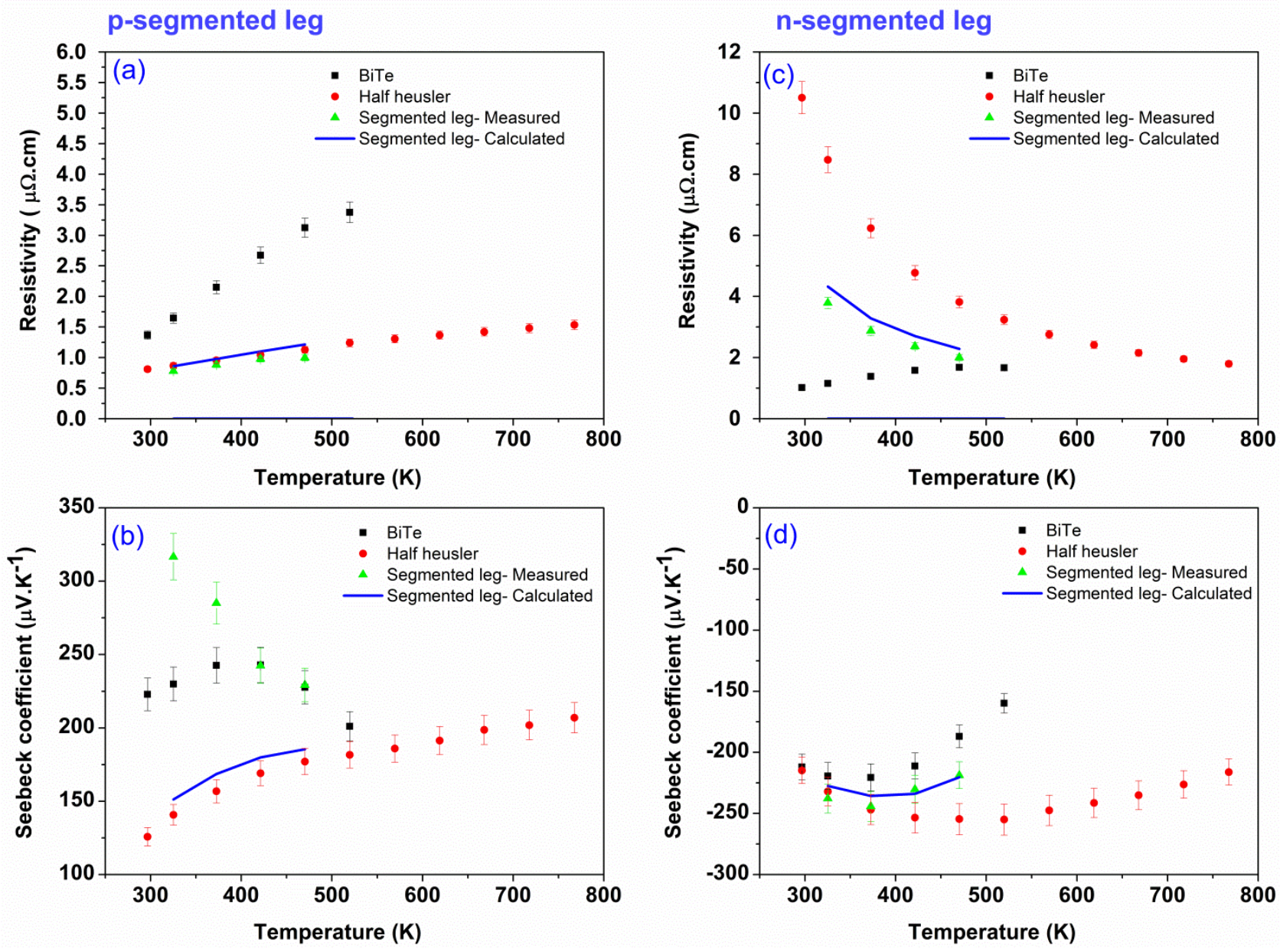

Fig. 5. Resistivity and Seebeck coefficient of $p$-type (a, b) and $n$-type segmented leg (c, d) measured by ZEM3.

\subsection{Output power generating characteristics of segmented legs}

The output power characteristics of the obtained segmented legs at different hot side and cold side temperatures are shown in Fig. $6 \mathrm{a}$ and $6 \mathrm{~b}$. At $\Delta T=550 \mathrm{~K}$, the $p$-type segmented leg generated a maximum open circuit voltage of $115 \mathrm{mV}$ and maximum current of $1.8 \mathrm{~A}$, giving a power output of $49.2 \mathrm{~mW}$ and a power density of $0.3 \mathrm{~W} \cdot \mathrm{cm}^{-2}$. The open voltage and maximum current of the $n$ segmented leg were $102 \mathrm{mV}$ and $1.6 \mathrm{~A}$, respectively under hot side/cold side temperatures of 873 and $323 \mathrm{~K}$, corresponding to a maximum power output of $40.6 \mathrm{~mW}$ and a power density of 0.25 $\mathrm{W} \cdot \mathrm{cm}^{-2}$. It is worth noticing that in this test setup, the electrode at the cold side of the legs is made merely by Ag paste and has not been optimized yet. The Ag paste after drying can introduce a porous layer that results in a large contact resistance observed in Ref $[2,46]$ and therefore negatively influences the overall thermoelectric outputs. 

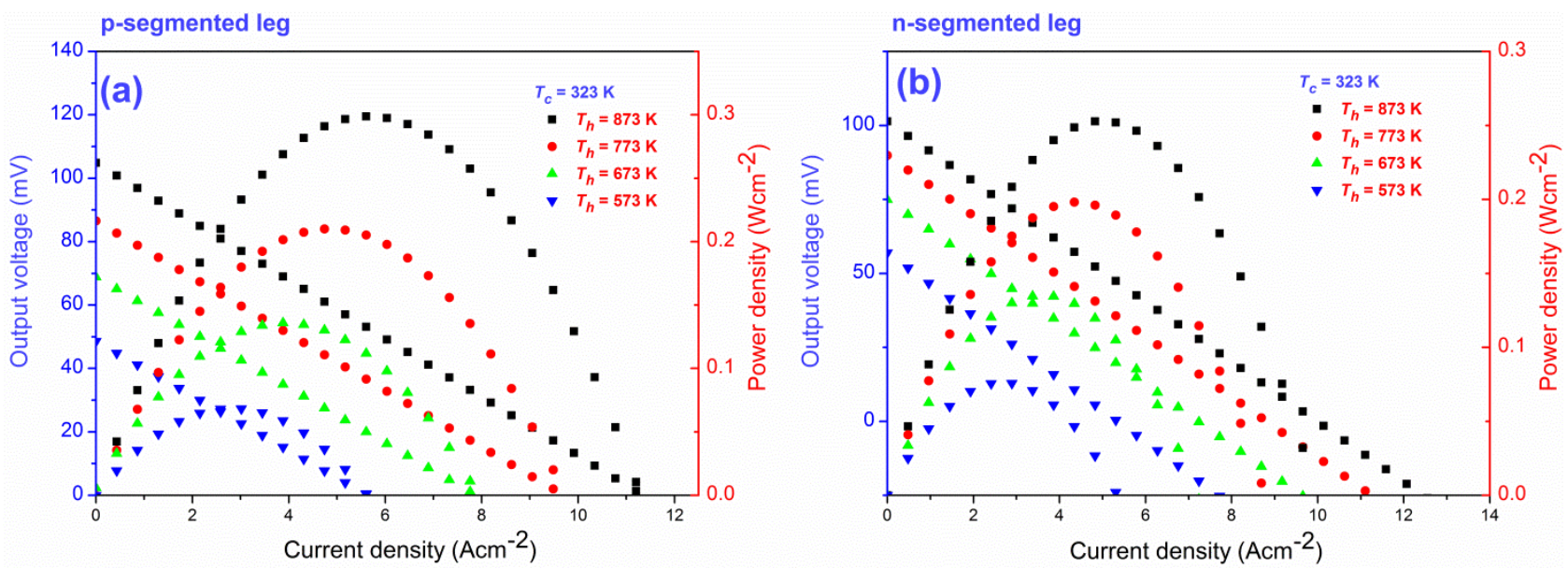

Fig. 6. Output voltage vs. current density characteristics of obtained $p$-type (a) and $n$-type segmented legs (b).

Table I. Comparision of Heusler and half-Heusler-based modules

\begin{tabular}{|c|c|c|c|c|c|}
\hline Module & Material & $\begin{array}{c}\text { Temperature } \\
\text { gradient } \\
\Delta T(\mathrm{~K})\end{array}$ & $\begin{array}{c}\text { Legs } \\
\text { dimensions } \\
(\mathrm{mm})\end{array}$ & $\begin{array}{c}\boldsymbol{P}_{\max } \\
(\mathrm{mW})\end{array}$ & $\begin{array}{c}\text { Power } \\
\text { density } \\
\left(\mathrm{W} \cdot \mathrm{cm}^{-2}\right)\end{array}$ \\
\hline $\begin{array}{c}\text { Heusler } 1 \\
\text { Mikami } \\
\text { [47] }\end{array}$ & $\begin{array}{l}p-\mathrm{Fe}_{2} \mathrm{VAl}_{0.9} \mathrm{Si}_{0.1} \\
n-\mathrm{Fe}_{2} \mathrm{~V}_{0.9} \mathrm{Ti}_{0.1} \mathrm{Al}\end{array}$ & 280 & $\begin{array}{l}\text { 36-times } \\
\text { diameter } \\
5 \times 5\end{array}$ & 940 & 0.133 \\
\hline $\begin{array}{c}\text { Heusler } 2 \\
\text { Mikami } \\
\text { [3] }\end{array}$ & $\begin{array}{c}p-\mathrm{Fe}_{2} \mathrm{~V}_{0.84} \mathrm{Ti}_{0.16} \mathrm{Al}_{0.97} \mathrm{Sb}_{0.03} \\
n-\mathrm{Fe}_{3} \mathrm{VAl}_{0.9} \mathrm{Si}_{0.07} \mathrm{Sb}_{0.03}\end{array}$ & 280 & $\begin{array}{c}\text { 36-times } \\
4.5 \times 4.5 \times \\
4.2\end{array}$ & 2500 & 0.342 \\
\hline Poon [4] & $\begin{array}{l}p-\mathrm{Hf}_{0.3} \mathrm{Zr}_{0.7} \mathrm{CoSn}_{0.3} \mathrm{Sb}_{0.7} \\
n-\mathrm{Hf}_{0.6} \mathrm{Zr}_{0.4} \mathrm{NiSn}_{0.995} \mathrm{Sb}_{0.005}\end{array}$ & 704 & 2 legs & 423 & - \\
\hline $\begin{array}{c}\text { Sascha } \\
{[40]}\end{array}$ & $n-\mathrm{Ti}_{0.33} \mathrm{Zr}_{0.33} \mathrm{Hf}_{0.33} \mathrm{NiSn}$ & 565 & $\begin{array}{l}\text { 4-times } \\
2 \times 2 \times 4\end{array}$ & 44 & 0.275 \\
\hline This work & $\begin{array}{c}\mathrm{Hf}_{0.5} \mathrm{Zr}_{0.5} \mathrm{CoSn}_{0.2} \mathrm{Sb}_{0.8} / \mathrm{Bi}_{0.6} \mathrm{Sb}_{1.4} \mathrm{~T} \\
n-\mathrm{Ti}_{0.6} \mathrm{Hf}_{0.4} \mathrm{NiSn}_{3} / \mathrm{Bi}_{2} \mathrm{Te}_{3}\end{array}$ & 550 & $4 \times 4 \times 8$ & 49.2 & 0.3 \\
\hline
\end{tabular}

The stability of the segmented legs, evaluated by recording the change of thermoelectric outputs during several thermal cycles, is presented in Fig. 7. After the $6^{\text {th }}$ cycle, the maximum voltage and power density of the $p$-type segmented leg decreased by $4.8 \%$ and $5.5 \%$, respectively compared with those obtained from the first cycle. As for the $n$-type segmented leg, the resulted maximum power density reduced by $5.4 \%$ after the $6^{\text {th }}$ cycle, and the highest voltage dropped by $3.9 \%$. The 
degradation of the output thermoelectric performance can be attributed to several possible reasons. The first reason could be the expansion of the interlayer between BiTe and $\mathrm{Ag}_{10} \mathrm{Sn}$, as observed from the microstructural analysis (see Fig. 2e, 2f, 2l, and 2k). As for the $p$-type leg, we observe shown more porosity of the solder layer probably due to diffusion of Sn into BiTe, which has also been observed in Ref. [29,33] and could influence the generated current (Fig. 2a and 2b). The measured contact resistance showed an increase at temperature approaching $525 \mathrm{~K}$ (Fig. 4). The second reason may be due to the increase of total TE leg resistance by the surface oxidation of the TE materials in the testing environment (air) and the sublimation of highly volatile elements, especially $\mathrm{Sb}$ in $\mathrm{HH}$ and BiTe [48,49]. The reduction of the maximum output voltage might result from the increase in thermal contact resistance between the TE elements and the alumina substrate during cycling. In addition, the effect of uneven deformation of alumina ceramic substrate as a result of high thermal gradient in the joining direction (which is known as Mayer-Marschall effect) also increases the thermal contact resistance of the tested TE leg [16].
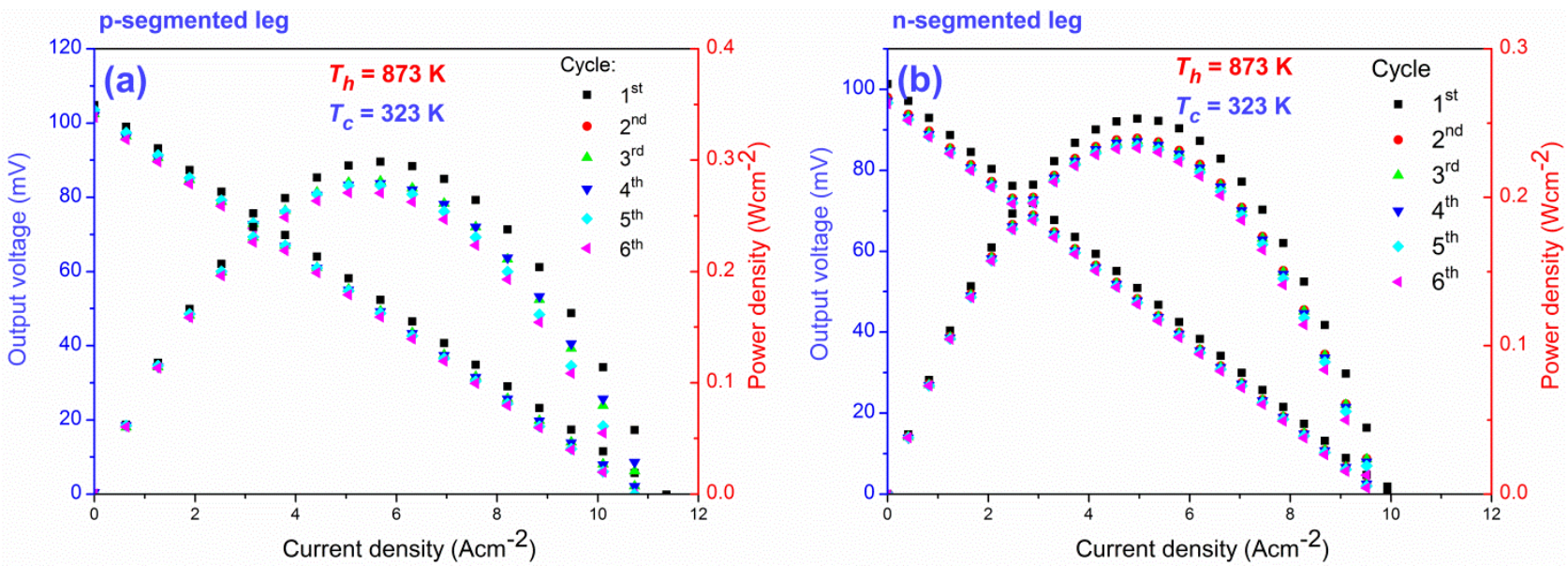

Fig. 7. Stability test of obtained segmented $p$-type segmented leg (a) and $n$-type segmented leg (b).

\section{Conclusion}

We have successfully segmented $p$ - and $n$-type BiTe and HH using a two-step fast hot pressing process and subsequently characterized the segmented legs. Microstructural and chemical elements analyses of the joint interfaces showed good contact and no sign of cracks at the joining between the materials. The diffusion of tin from the solder alloy into BiTe was observed with a penetration depth of $10 \mu \mathrm{m}$. Regardless, thermopower microprobe scanning in the vicinity of the joining interface showed no detrimental change of the Seebeck coefficient of the BiTe and $\mathrm{HH}$ of the segmented leg after joining, at least within the scale of $50 \mu \mathrm{m}$. The area specific contact resistance of the $p$-type $\mathrm{BiTe} / \mathrm{Ag}_{10} \mathrm{Sn} / \mathrm{Ag} / \mathrm{HH}$ structure was measured to be $50 \mu \Omega \cdot \mathrm{cm}^{2}$ at room temperature 
and increased to $75 \mu \Omega \cdot \mathrm{cm}^{2}$ at $523 \mathrm{~K}$. For the $n$-type leg, the contact resistance was found to be 50 $\mu \Omega \cdot \mathrm{cm}^{2}$ at room temperature and slightly decreased to $35 \mu \Omega \cdot \mathrm{cm}^{2}$ at $523 \mathrm{~K}$. The electrical resistivity and thermopower of the segmented legs were in good agreement with calculation with the exception of the Seebeck coefficient of the $p$-type segmented leg which was twice the calculated value due to a geometric measurement error inherent with the sample. The thermoelectric output tests in air environment of $p$-type segmented leg shows a maximum power density of $0.3 \mathrm{~W} \cdot \mathrm{cm}^{-2}$ under a temperature gradient of $550 \mathrm{~K}$. For the $n$-type segmented leg, the power density was $0.25 \mathrm{~W} \cdot \mathrm{cm}^{-2}$. After 6 thermal cycles with a hot-side temperature of $873 \mathrm{~K}$, the performance decreased by $5.5 \%$ and $5.4 \%$ for the $p$-type leg and $n$-type leg, respectively. The introduced process to join $\mathrm{HH}$ and $\mathrm{BiTe}$ is therefore promising for the development of a segmented thermoelectric generator.

\section{Acknowledgements}

The authors acknowledge the support from Copenhagen Cleantech Cluster for the research work (in Project 48062 $\mathrm{X}-\mathrm{CCC}$ ) and the Programme Commission on Energy and Environment (EnMi), which is part of the Danish Council for Strategic Research (Contract No. 10-093971), for sponsoring the research of the OTE-Power Project. We thank Professor Bo Brummerstedt Iversen for providing access to the potentional Seebeck microprobe Panco, which is sponsored by the Danish National Research Foundation (DNRF93).

\section{Appendix}

Table II. Chemical composition of interdiffusion layer between BiTe and solder alloy $\mathrm{Ag}_{10} \mathrm{Sn}$

\begin{tabular}{lllllll}
\hline Fig. 2 & \multicolumn{5}{c}{ Point } & \multicolumn{5}{c}{ Element composition (at.\%) } \\
\cline { 3 - 7 } & & $\mathrm{Bi}$ & $\mathrm{Te}$ & $\mathrm{Sb} / \mathrm{Se}$ & $\mathrm{Ag}$ & $\mathrm{Sn}$ \\
\hline \multirow{2}{*}{$\mathrm{f}$} & (1) n-type BiTe part & 37.2 & 49.5 & $3.5 / 2.9$ & 2.2 & 4.9 \\
$\mathrm{f}$ & (2) Inter alloy 1 & 35.5 & 53.5 & $3.9 / 1.8$ & 0.3 & 5 \\
& (3) Inter alloy 2 & 2.8 & 0 & $5.3 / 0$ & 14.2 & 77.7 \\
& (4) Inter alloy 3 & 0.8 & 0 & $2.7 / 0.2$ & 66 & 30.4 \\
& & & & & & \\
b & (1) p-type BiTe part & 6.9 & 47.6 & $30.3 / 0.3$ & 7.6 & 7.3 \\
& (2) Inter alloy 1 & 2.1 & 35.8 & $15.9 / 0$ & 3.3 & 43.1 \\
& (3) Inter alloy 2 & 0.5 & 0.4 & $1.44 / 0$ & 64.6 & 33.1 \\
& (4) Inter alloy 3 & 4 & 0 & $12.8 / 0.6$ & 6.1 & 76.5
\end{tabular}

\section{References}

[1] D. M. Rowe, Thermoelectrics Handbook: Macro to Nano (Taylor and Franics Group, 2006).

[2] W. Liu, Q. Jie, H. S. Kim, and Z. Ren, Acta Materialia 87, 357 (2015).

[3] K. K. M. Mikami, and S. Tanaka, Mater. Trans. 52, 1546 (2011).

[4] S. J. W. Poon, D.; Zhu, S.; Xie, W.J.; Tritt, T.M.; Thomas, P.; Venkatasubramanian, R., J. Mater. Res. 26, 2795 (2011). 
[5] H. Scherrer, in CRC Handbook of Thermoelectrics, ed. D.M. Rowe (CRC Press, 2006), p. 211.

[6] H. J. Goldsmid, Springer series in Materials Science 3 (2001).

[7] N. V. Nong, L. Han, L. T. Hung, H. N. Pham, S. H. Spangsdorf, A. Roch, L. Stepien, and N. Pryds, in Proceeding of International conference on thermoelectrics (2015).

[8] N. V. Nong, L. T. Hung, H. Li, R. Bjørk, P. H. Ngan, T. C. Holgate, B. Balke, G. J. Snyder, S. Linderoth, N. Pryds, Energy Technol. 3, 1143 (2015).

[9] T. C. Holgate, H. Li, N. Wu, E. D. Bøjesen, M. Christensen, B. B. Iversen, N. V. Nong, N. Pryds, J. Alloys. Compd. 582, 827 (2014).

[10] L. H. T. H. Le, E. Stamate, H. N. Pham, B. Balke, S. Linderoth, N. Van Nong, and N. Pryds, in MRS Fall Meeting \& Exhibit, Boston, MA, 2013).

[11] R. Bjørk, J. Electron. Mater. 44, 2869 (2015).

[12] D. G. Zhao, H. Geng, and L. Chen, Int. J. Appl. Ceram. Technol. 9, 4, 733 (2012).

[13] X. Y. L. D. G. Zhao, Y. H. Cai, W. Jiang, and L. D. Chen, Mater. Sci. Forum 631, 313 (2009).

[14] D.E. Wesolowski, R.S. Goeke, A.M. Morales, S.H. Goods, P.A. Sharma, M.P. Saavedra, K.R. Reyes-Gil, W.C.G. Neel, N.Y.C. Yang, and C.A. Apblett, J. Mater. Res 27, 1149 (2012).

[15] M. Kambe, T. Jinushi, and Z. Ishijima, J. Electron. Mater. 43, 1959 (2013).

[16] M. Zebarjadi, K. Esfarjani, M. S. Dresselhaus, Z. F. Ren, and G. Chen, Energy Environ. Sci. 5, 5147 (2012).

[17] J. J. Shen, S. N. Zhang, S. H. Yang, Z. Z. Yin, T. J. Zhu, and X. B. Zhao, J. Alloys Compd. 509, 161 (2011).

[18] T.-S. Kim and B.-S. Chun, J. Alloys Compd. 437, 225 (2007).

[19] E. Maciá, in Thermoelectric Materials: Advances and Applications, Pan Stanford (2015), p.340.

[20] T. N. S. Hirono, M. Okamura, Patent WO2006067986 A1 (2007).

[21] M. S. F.-D. Börner, B. Feng, W. Lippmann, H.-P. Martin, A. Michaelis, and A. Hurtado, J. Mater. Res. 29, 1771 (2014).

[22] E. J. T. J. J. D’Angelo, F. Ren, B. D. Hall, E. Case, H. Schock, M. Kanatzidis, D. Y. Chung, and T. P. Hogan, MRS Online Proc. Libr. 1044 (2007).

[23] S. LeBlanc, Sustain. Mater. Technol. 1, 26 (2014).

[24] L. M. Pavlova, Y. I. Shtern, and R. E. Mironov, High Temperature 49, 369 (2011).

[25] K. N. R. Taylor, British J. Appl. Phys. 12 (1958).

[26] S. Hirono, T. Naba and M. Okamura, in Patent EP1835551A1 (2007).

[27] W. Brostow, T. Datashvili, H. E. Hagg Lobland, T. Hilbig, L. Su, C. Vinado, and J. White, J. Mater. Research 27, 2930 (2012).

[28] S.-W. Chen, C.-C. Chen, W. Gierlotka, A.-R. Zi, P.-Y. Chen, and H.-J. Wu, J. Electron. Mater. 37, 992 (2008). 
[29] Y. C. Lan, D. Z. Wang, G. Chen, and Z. F. Ren, Appl. Phys. Lett. 92, 101910 (2008).

[30] R. Z. K. T. Wojciechowski, J. Leszczynski, P. Nieroda, M. Schmidt, R. Gajerski, and E. Aleksandrova, Proceeding of the $9^{\text {th }}$ European conference on Thermoelectrics, p.467 (2012).

[31] W. P. Lin, D. E. Wesolowski, and C. C. Lee, J. Mater. Sci.: Mater. Electron. 22, 1313 (2011).

[32] M. F. D. C. Valette, R. Voytovych, and N. Eustathopoulos, Scr. Mater. 52, 1 (2005).

[33] C. H. L. C. N. Liao, and W. J. Chen, Electrochem. Solid-State Lett. 10, 23 (2007).

[34] T. Y. Lin, C. N. Liao, and A. T. Wu, J. Electron. Mater. 41, 153 (2011).

[35] N. V. Nong, L. T. Hung; H. Li; P. H. Ngan, N. Pryds, in Proceeding of the $34^{\text {th }}$ International Conference on Thermoelectrics, Dresden, Germany, (2015).

[36] S. Fujita, K. Ito, in Quantum theory of Conducting Matter, (Springer New York, 2007). p. 195

[37] L. K. P. Fiflis, D. Andruczyk, D. Curreli, and D. N. Ruzic, J. Nucl. Mater. 438, 224 (2013).

[38] B. L. Q. Zhang, Y. Lan, K. Lukas, W. Liu, K. Esfarjani, C. Opeil, D. Broido, G. Chen, and Z. Ren, Proc. Natl. Acad. Sci. U. S. A. 110, 13261 (2013).

[39] D. Zhao, H. Geng, and X. Teng, J. Alloys. Compd. 517, 198 (2012).

[40] S. Populoh, O. Brunko, K. Gałązka, W. Xie, and A. Weidenkaff, Mater. 6, 1326 (2013).

[41] K. Arai, M. Matsubara, Y. Sawada, T. Sakamoto, T. Kineri, Y. Kogo, T. Iida, and K. Nishio, J. Electron. Mater. 41, 1771 (2012).

[42] H. O. O. Yamashita, S. Tomiyoshi, J. Mater. Scien. 39, 5653 (2004).

[43] W. A. Harrison, in Solid State Theory, (Dover Publications 2012).

[44] Y. Apertet, H. Ouerdane, C. Goupil, P. Lecoeur, Energ. Convers. Manag. 93, 160 (2015).

[45] J. de Boor, C. Gloanec, H. Kolb, R. Sottong, P. Ziolkowski, and E. Müller, J. Alloys Compd 632, 348 (2015).

[46] D. K. Aswal, R. Basu, and A. Singh, Energ. Conver. Manage. 114, 50 (2016).

[47] M. Mikami, K. Kobayashi, T. Kawada, K. Kubo, and N. Uchiyama, J. Electron. Mater 38, 1121 (2009).

[48] H. S. Kim, W. Liu and Z. Ren, Energ. Environ. Sci., 10, 69 (2017).

[49] H. H. S. a. M. S. El-Genk, AIP Conf. Proc. 608, 998 (2002). 


\section{Figure captions}

Fig.1. Thermoelectric properties of BiTe and HH in $p$-type segmented leg (a-d) and $n$-type segmented leg (e-h).

Fig. 2. SEM images and EDS chemical analysis at the joint interface of $p$-type (a-d), $n$-type (e-h) segmented leg before heat treatment and (i-m) $n$-type segmented leg after heat treatment. After heat treatment, the $p$ type segmented leg delaminated, so no further microstructural analysis had been conducted.

Fig. 3. Scanning Seebeck analysis at the joint interface of $p$-type (a) and $n$-type (b, c) segmented legs Fig. 4. Temperature - dependence of area specific contact resistance of the $p$ - and $n$-type segmented legs

Fig. 5. Resistivity and Seebeck coefficient of the $p$-type (a, b) and $n$-type segmented leg (c, d) measured by ZEM 3.

Fig. 6. Output voltage vs. current density characteristics of obtained $p$-type (a) and $n$-type segmented leg (b).

Fig. 7. Stability test of obtained $p$-type (a) and $n$ - type segmented leg (b). 

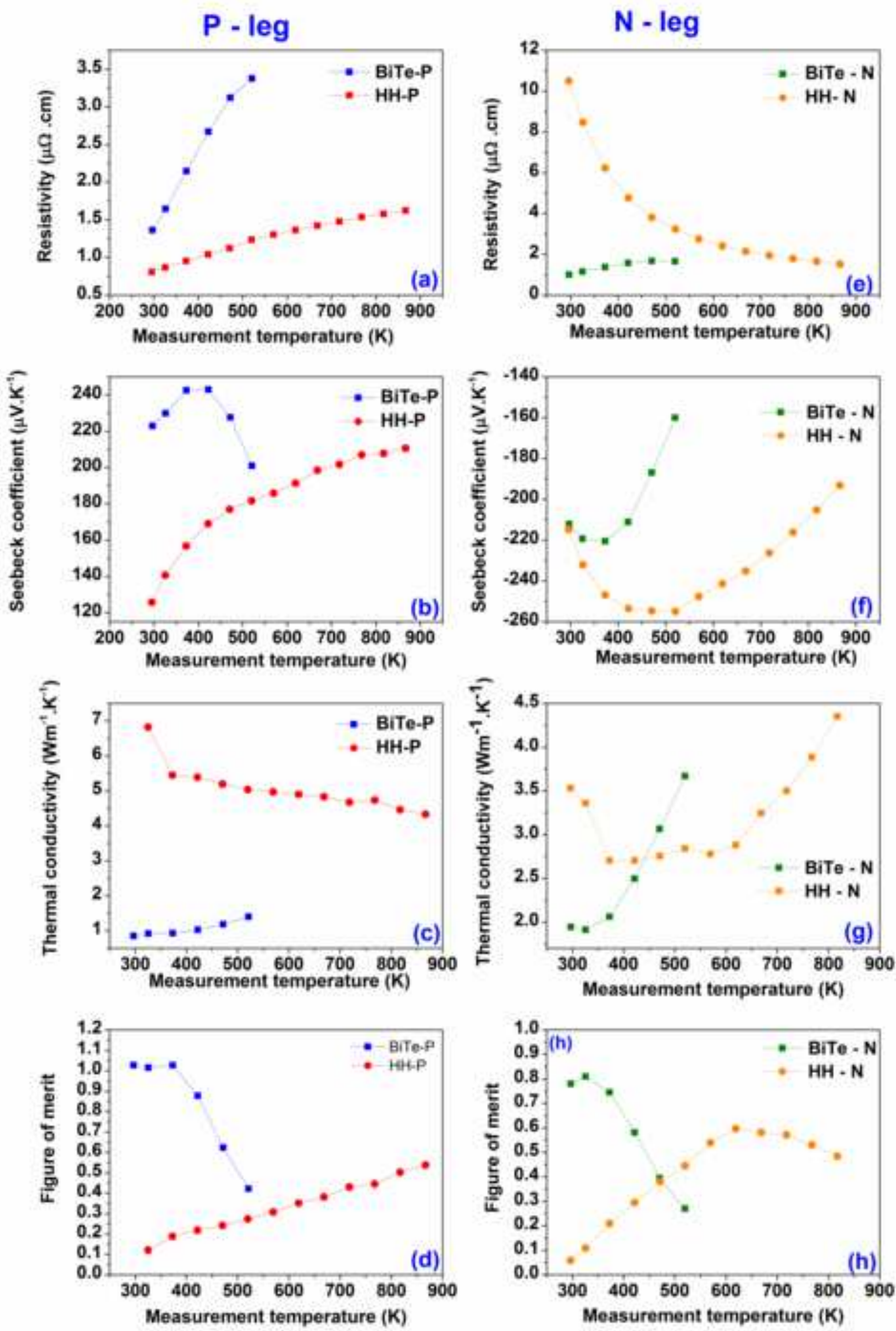

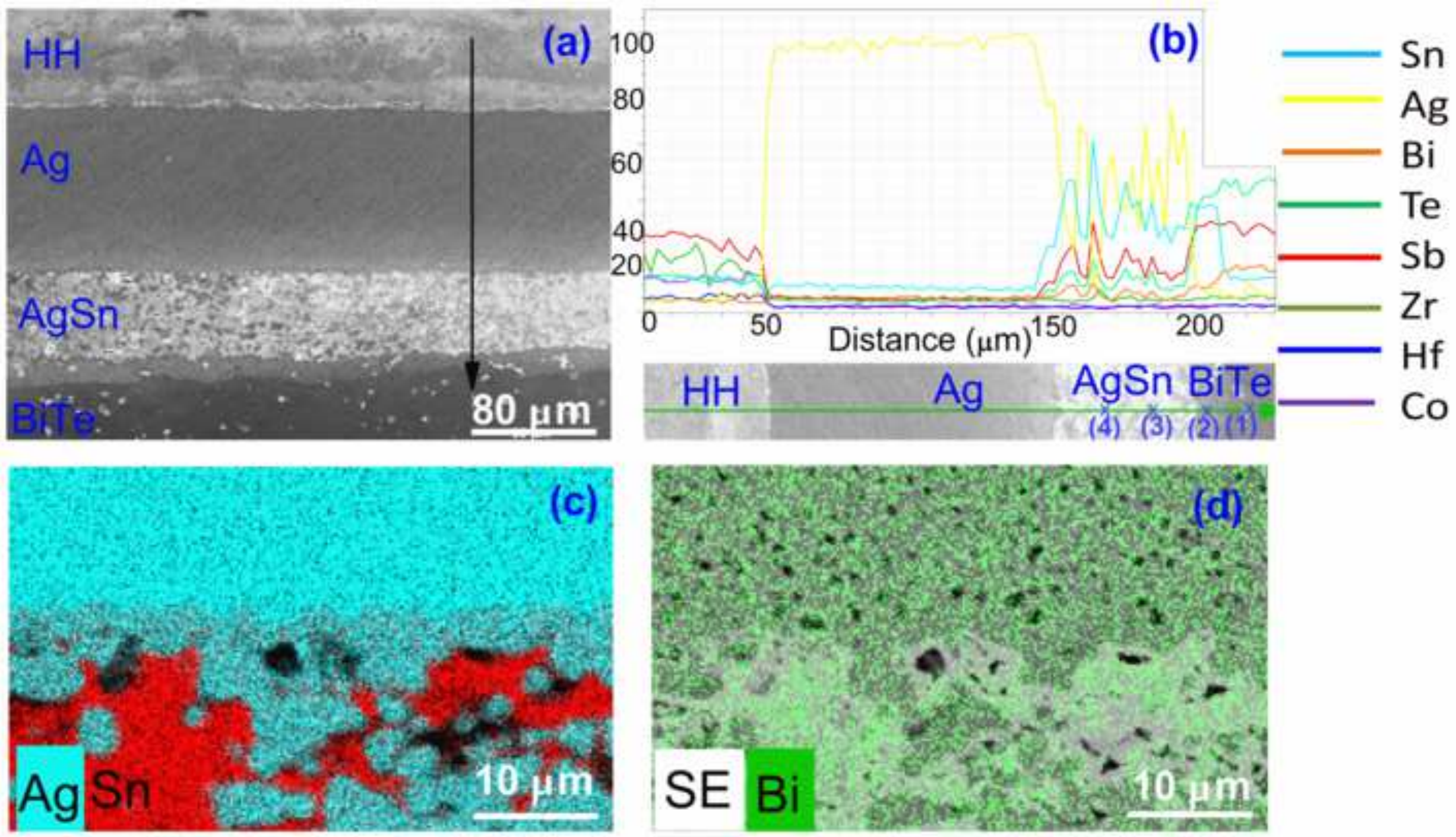

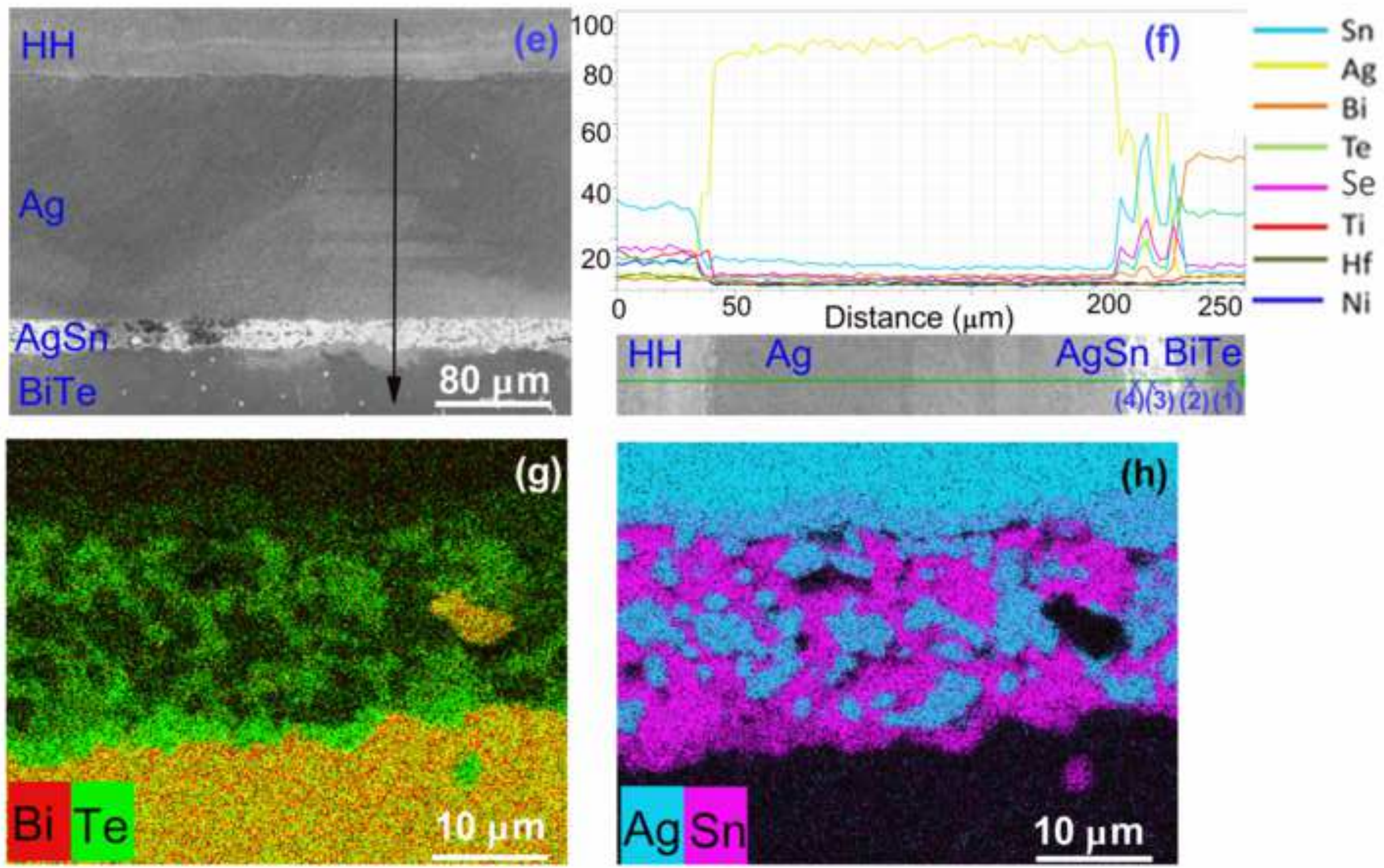

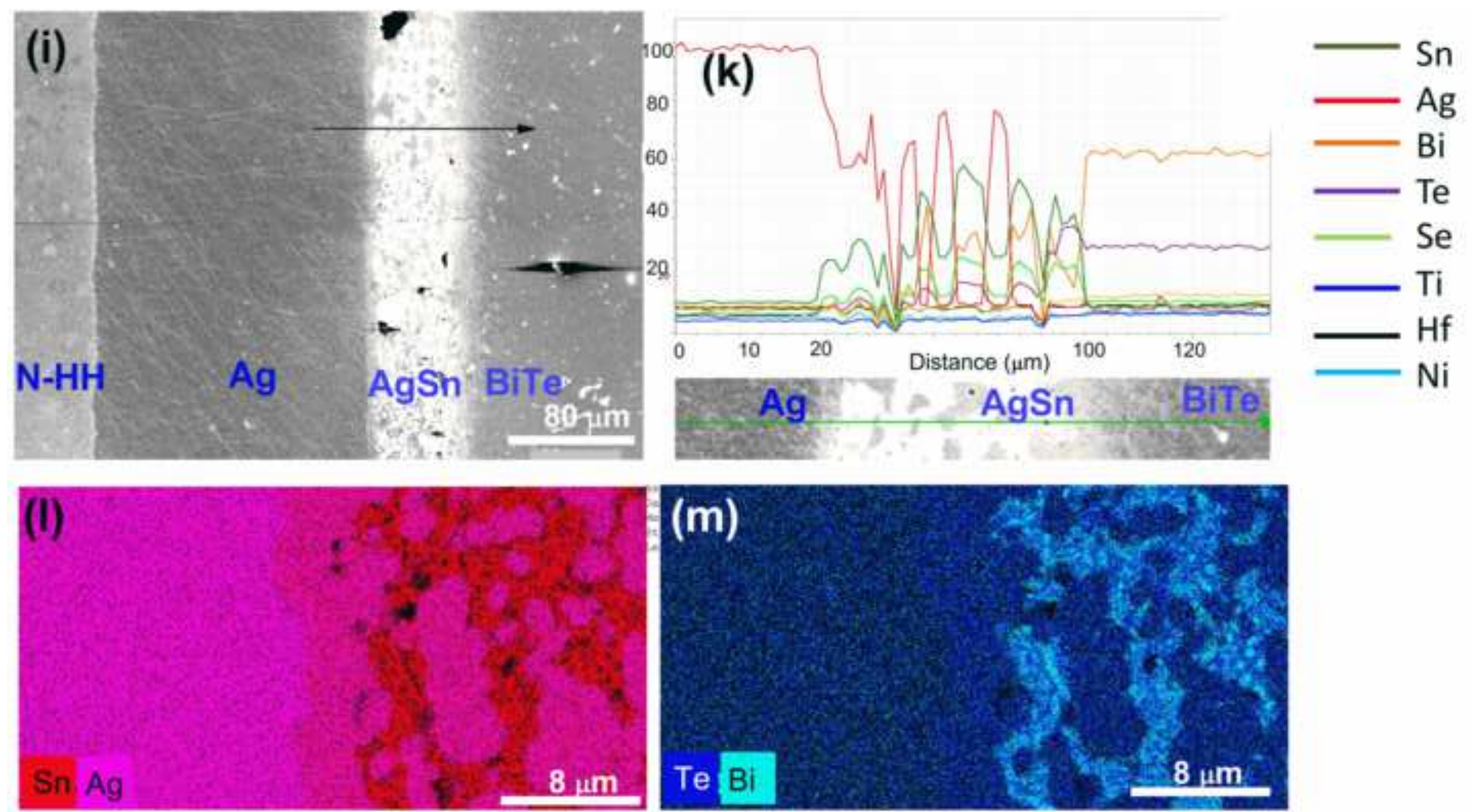

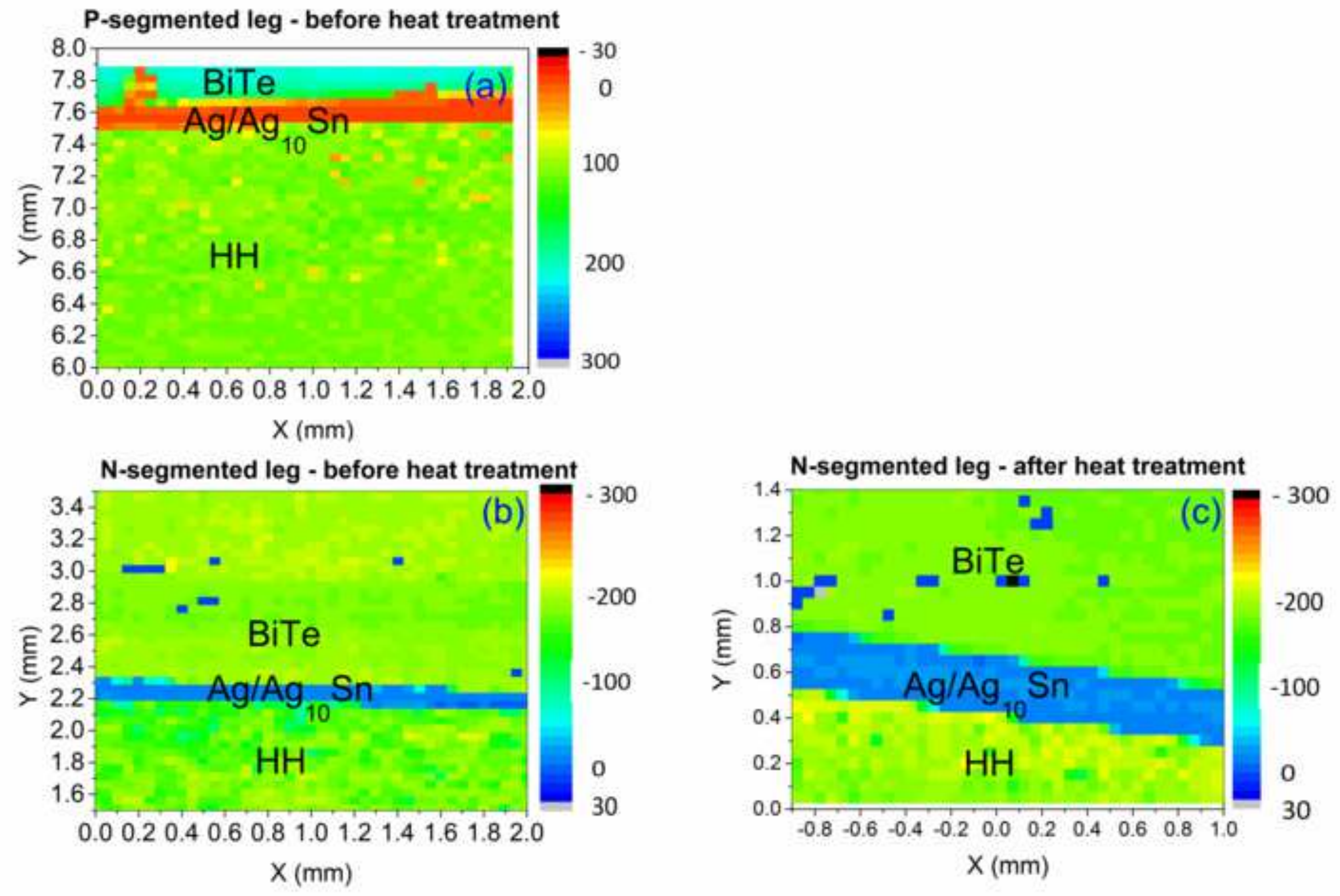


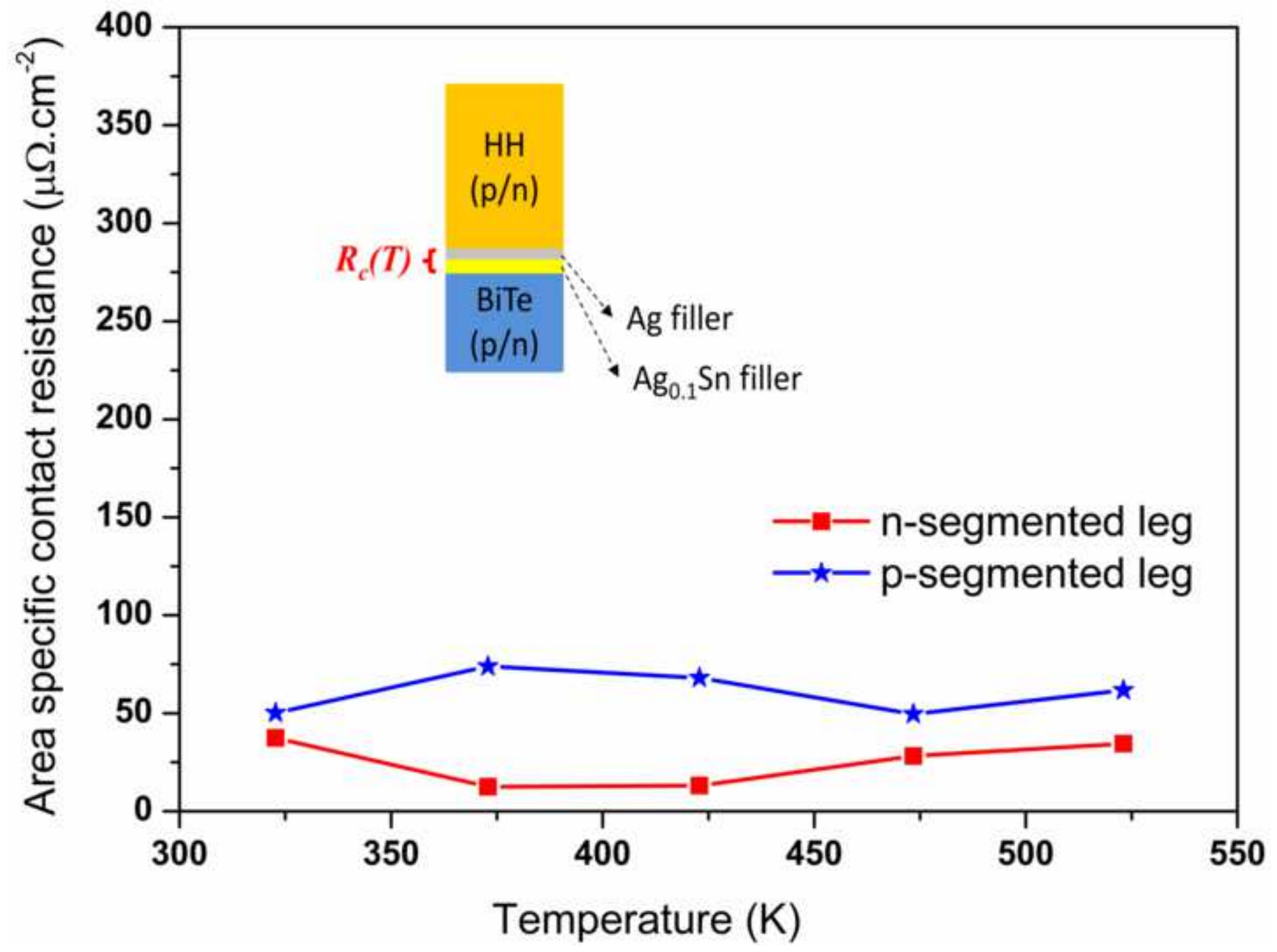



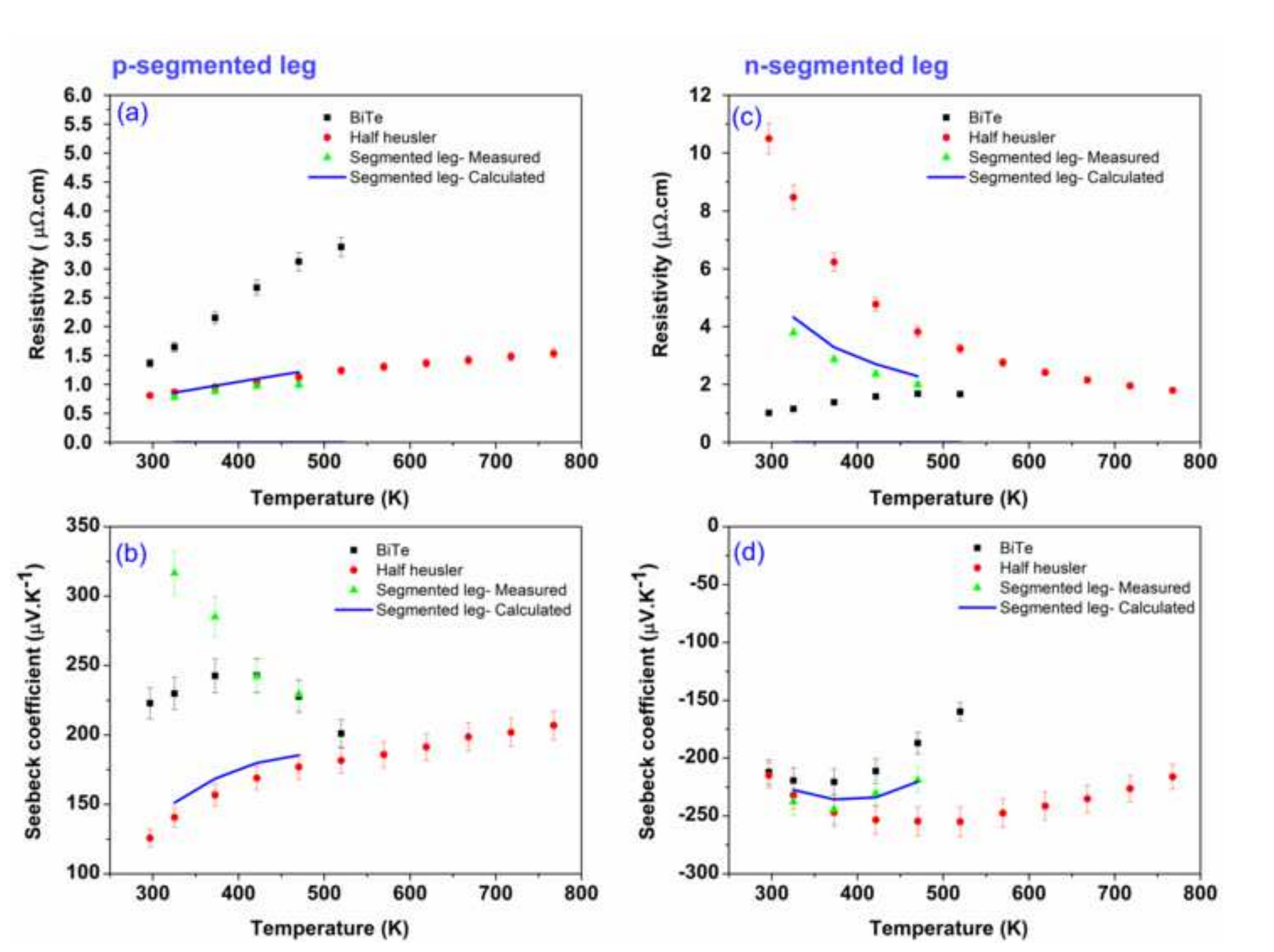

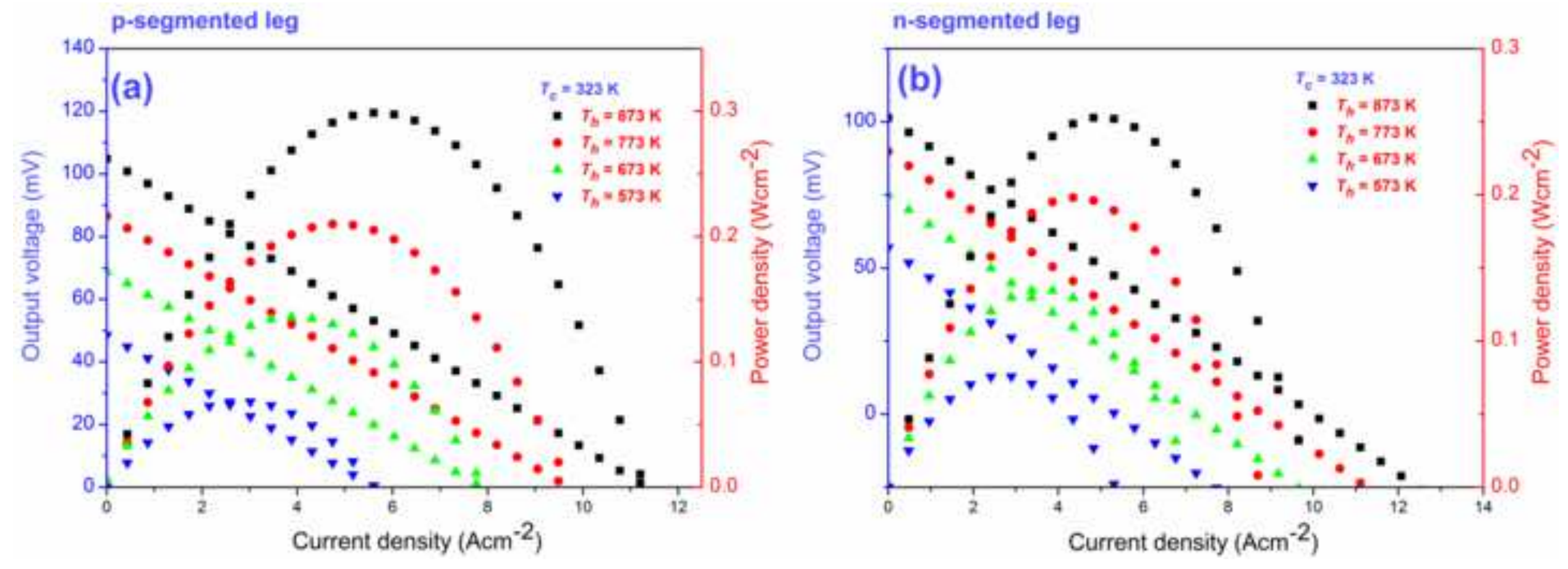

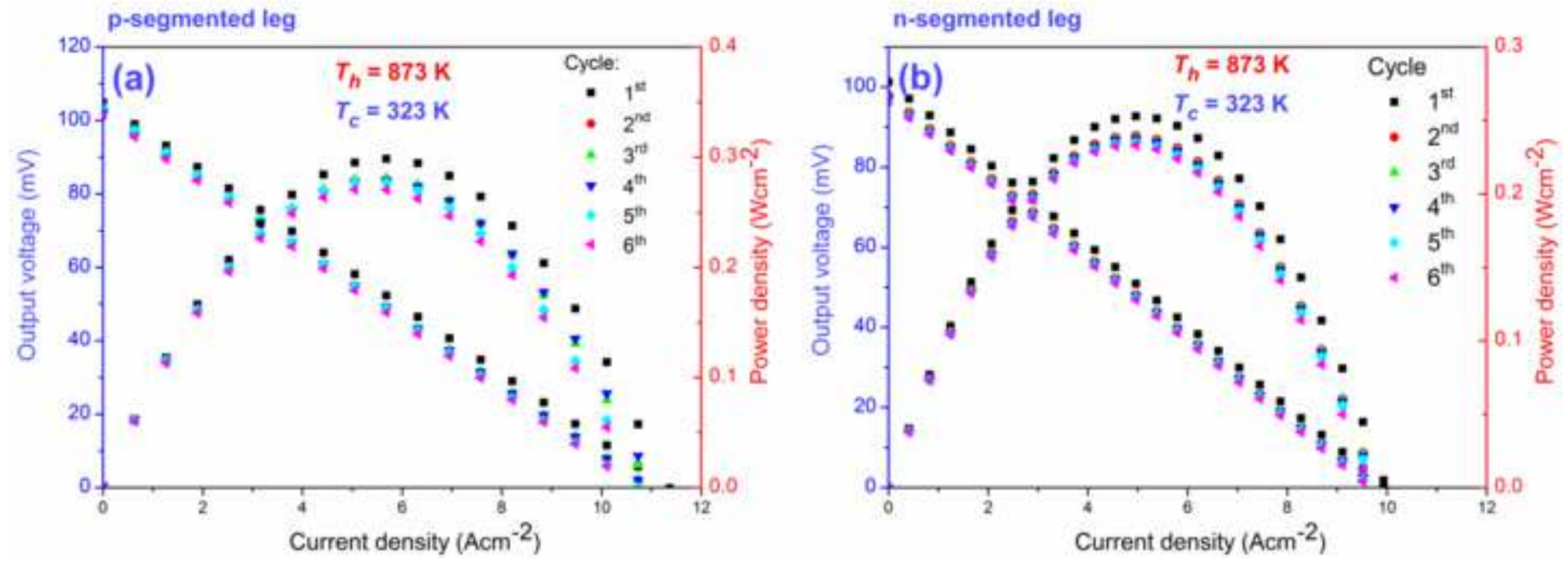
Table I. Comparision of Heusler and half-Heusler-based modules

\begin{tabular}{|c|c|c|c|c|c|}
\hline Module & Material & $\begin{array}{c}\text { Temperature } \\
\text { gradient } \\
\Delta T(\mathrm{~K})\end{array}$ & $\begin{array}{c}\text { Legs } \\
\text { dimensions } \\
(\mathrm{mm})\end{array}$ & $\begin{array}{c}\boldsymbol{P}_{\max } \\
(\mathrm{mW})\end{array}$ & $\begin{array}{c}\text { Power } \\
\text { density } \\
\left(\mathrm{Wcm}^{-2}\right)\end{array}$ \\
\hline Heusler 1 & $p-\mathrm{Fe}_{2} \mathrm{VAl}_{0.9} \mathrm{Si}_{0.1}$ & 280 & 36-times & 940 & 0.133 \\
\hline Mikami & $n-\mathrm{Fe}_{2} \mathrm{~V}_{0.9} \mathrm{Ti}_{0.1} \mathrm{Al}$ & & diameter 5 & & \\
\hline$[47]$ & & & $\times 5$ & & \\
\hline Heusler 2 & $p-\mathrm{Fe}_{2} \mathrm{~V}_{0.84} \mathrm{Ti}_{0.16} \mathrm{Al}_{0.97} \mathrm{Sb}_{0.03}$ & 280 & 36-times & 2500 & 0.342 \\
\hline Mikami & $n-\mathrm{Fe}_{3} \mathrm{VAl}_{0.9} \mathrm{Si}_{0.07} \mathrm{Sb}_{0.03}$ & & $4.5 \times 4.5 \times$ & & \\
\hline [3] & & & 4.2 & & \\
\hline Poon [4] & $p-\mathrm{Hf}_{0.3} \mathrm{Zr}_{0.7} \mathrm{CoSn}_{0.3} \mathrm{Sb}_{0.7}$ & 704 & 2 legs & 423 & - \\
\hline & $n-\mathrm{Hf}_{0.6} \mathrm{Zr}_{0.4} \mathrm{NiSn}_{0.995} \mathrm{Sb}_{0.005}$ & & & & \\
\hline Sascha & $n-\mathrm{Ti}_{0.33} \mathrm{Zr}_{0.33} \mathrm{Hf}_{0.33} \mathrm{NiSn}$ & 565 & 4-times & 44 & 0.275 \\
\hline$[40]$ & & & $2 \times 2 \times 4$ & & \\
\hline \multirow[t]{2}{*}{ This work } & $\underset{\mathrm{Hf}_{0.5} \mathrm{Zr}_{0.5} \mathrm{CoSn}_{0.2} \mathrm{Sb}_{0.8} / \mathrm{Bi}_{0.6} \mathrm{Sb}_{1.4} \mathrm{~T}}{\mathrm{e}_{3}}$ & 550 & $4 \times 4 \times 8$ & 49.2 & 0.3 \\
\hline & $n-\mathrm{Ti}_{0.6} \mathrm{Hf}_{0.4} \mathrm{NiSn} / \mathrm{Bi}_{2} \mathrm{Te}_{3}$ & 550 & $4 \times 4 \times 8$ & 40.6 & 0.25 \\
\hline
\end{tabular}


Table II. Chemical composition of interdiffusion layer between BiTe and solder alloy $\mathrm{Ag}_{10} \mathrm{Sn}$

\begin{tabular}{lllllll}
\hline Fig. 2 & \multicolumn{5}{c}{ Point } & \multicolumn{5}{c}{ Element composition (at.\%) } \\
\cline { 3 - 7 } & & $\mathrm{Bi}$ & $\mathrm{Te}$ & $\mathrm{Sb} / \mathrm{Se}$ & $\mathrm{Ag}$ & $\mathrm{Sn}$ \\
\hline \multirow{4}{*}{$\mathrm{f}$} & (1) n-type BiTe part & 37.2 & 49.5 & $3.5 / 2.9$ & 2.2 & 4.9 \\
& (2) Inter alloy 1 & 35.5 & 53.5 & $3.9 / 1.8$ & 0.3 & 5 \\
& (3) Inter alloy 2 & 2.8 & 0 & $5.3 / 0$ & 14.2 & 77.7 \\
& (4) Inter alloy 3 & 0.8 & 0 & $2.7 / 0.2$ & 66 & 30.4 \\
& & & & & & \\
b & (1) p-type BiTe part & 6.9 & 47.6 & $30.3 / 0.3$ & 7.6 & 7.3 \\
& (2) Inter alloy 1 & 2.1 & 35.8 & $15.9 / 0$ & 3.3 & 43.1 \\
& (3) Inter alloy 2 & 0.5 & 0.4 & $1.44 / 0$ & 64.6 & 33.1 \\
& (4) Inter alloy 3 & 4 & 0 & $12.8 / 0.6$ & 6.1 & 76.5
\end{tabular}

